\title{
Title:
}

\section{Tight nanoscale clustering of Fcy-receptors using DNA origami promotes phagocytosis}

\author{
Nadja Kern ${ }^{1,2}$, Rui Dong ${ }^{1,2}$, Shawn M. Douglas ${ }^{1}$, Ronald D. Vale ${ }^{1,2,3 \star}$ and Meghan A. \\ Morrissey ${ }^{1,4,5 *}$ \\ ${ }^{1}$ Department of Cellular and Molecular Pharmacology, University of California San \\ Francisco, San Francisco, CA 94158 \\ ${ }^{2}$ Howard Hughes Medical Institute, University of California San Francisco, San \\ Francisco, CA 94158 \\ ${ }^{3}$ Howard Hughes Medical Institute Janelia Research Campus, Ashburn, VA 20147 \\ ${ }^{4}$ Department of Molecular, Cellular and Developmental Biology, University of California \\ Santa Barbara, CA 93106 \\ ${ }^{*}$ Corresponding Author \\ ${ }^{5}$ Lead contact
}




\section{Abstract}

2

3 Macrophages destroy pathogens and diseased cells through $\mathrm{Fc \gamma}$ receptor $(\mathrm{Fc \gamma R})$-driven

4 phagocytosis of antibody-opsonized targets. Phagocytosis requires activation of multiple

5 FcyRs, but the mechanism controlling the threshold for response is unclear. We

6 developed a DNA origami-based engulfment system that allows precise nanoscale

7 control of the number and spacing of ligands. When the number of ligands remains

8 constant, reducing ligand spacing from $17.5 \mathrm{~nm}$ to $7 \mathrm{~nm}$ potently enhances engulfment,

9 primarily by increasing efficiency of the engulfment-initiation process. Tighter ligand

10 clustering increases receptor phosphorylation, as well as proximal downstream signals.

11 Increasing the number of signaling domains recruited to a single ligand-receptor

12 complex was not sufficient to recapitulate this effect, indicating that clustering of multiple

13 receptors is required. Our results suggest that macrophages use information about local

14 ligand densities to make critical engulfment decisions, which has implications for the

15 mechanism of antibody-mediated phagocytosis and the design of immunotherapies. 


\section{Introduction}

18 Immune cells eliminate pathogens and diseased cells while limiting damage to healthy

19 cells. Macrophages, professional phagocytes and key effectors of the innate immune

20 system, play an important role in this process by engulfing opsonized targets bearing

21 'eat me' signals. One of the most common 'eat me' signals is the immunoglobulin G

22 ( $\lg G$ ) antibody, which can bind foreign proteins on infected cells or pathogens. IgG is

23 recognized by $F c \gamma$ receptors $(F c \gamma R)$ in macrophages that drive antibody-dependent

24 cellular phagocytosis (ADCP) (Dilillo, Tan, Palese, \& Ravetch, 2014; Erwig \& Gow,

25 2016; Nimmerjahn \& Ravetch, 2008). ADCP is a key mechanism of action for several

26 cancer immunotherapies including rituximab, trastuzumab, and cetuximab (Chao et al.,

27 2010; Uchida et al., 2004; Watanabe et al., 1999; Weiskopf et al., 2013; Weiskopf \&

28 Weissman, 2015). Exploring the design parameters of effective antibodies could provide

29 valuable insight into the molecular mechanisms driving ADCP.

31 Activation of multiple Fc $\gamma R s$ is required for a macrophage to engulf a three-dimensional

32 target. FcyR-IgG must be present across the entire target to drive progressive closure of

33 the phagocytic cup that surrounds the target (Griffin, Griffin, Leider, \& Silverstein, 1975).

34 In addition, a critical antibody threshold across an entire target dictates an all-or-none

35 engulfment response by the macrophage (Y. Zhang, Hoppe, \& Swanson, 2010).

36 Although the mechanism of this thresholded response remains unclear, receptor

37 clustering plays a role in regulating digital responses in other immune cells (Berger et

38 al., 2020; Davis \& van der Merwe, 2006; Holowka \& Baird, 1996; Kato et al., 2020; Ma,

39 Lim, Benda, Goyette, \& Gaus, 2020; Veneziano et al., 2020). FcyR clustering may also

40 regulate phagocytosis (Goodridge, Underhill, \& Touret, 2012). High resolution imaging

41 of macrophages has demonstrated that IgG-bound FcyRs form clusters (resolution of $42>100 \mathrm{~nm}$ ) within the plasma membrane (Lin et al., 2016; Lopes et al., 2017; Sobota et

43 al., 2005). These small clusters, which recruit downstream effector proteins such as

44 Syk-kinase and phosphoinositide 3-kinase, eventually coalesce into larger micron-scale

45 patches as they migrate towards the center of the cell-target synapse (Jaumouillé et al.,

46 2014; Lin et al., 2016; Lopes et al., 2017; Sobota et al., 2005). 
48 Prior observational studies could not decouple ligand clustering from other parameters, such as ligand number or receptor mobility. As a result, we do not have a clear picture of how ligand number or molecular spacing regulate signal activation. To directly assess such questions, we have developed a reconstituted system that utilizes DNA origami to manipulate ligand patterns on a single-molecule level with nanometer resolution. We

53 found that tightly spaced ligands strongly enhanced phagocytosis compared to the

54 same number of more dispersed ligands. Through manipulating the number and spacing of ligands on individual origami pegboards, we found that 8 or more ligands per cluster maximized FcyR-driven engulfment, and that macrophages preferentially engulfed targets that had receptor-ligand clusters spaced $\leq 7 \mathrm{~nm}$ apart. We demonstrated that tight ligand clustering enhanced receptor phosphorylation, and the generation of $\mathrm{PIP}_{3}$ and actin filaments-critical downstream signaling molecules-at the

60 phagocytic synapse. Together, our results suggest that the nanoscale clustering of

61 receptors may allow macrophages to discriminate between lower density background 62 stimuli and the higher density of ligands on opsonized targets. These results have 63 implications for the design of immunotherapies that involve manipulating FcyR-driven 64 engulfment.

\section{Results}

\section{Developing a DNA-based chimeric antigen receptor to study phagocytosis}

To study how isolated biochemical and biophysical ligand parameters affect engulfment,

72 developed a synthetic $T$ cell signaling system, in which we replaced the receptor-ligand

73 interaction (TCR-pMHC) with complimentary DNA oligos (Taylor, Husain, Gartner,

74 Mayor, \& Vale, 2017). We applied a similar DNA-based synthetic chimeric antigen

75 receptor to study engulfment signaling in macrophages. In our DNA-CAR $\gamma$ receptor, we

76 replaced the native extracellular ligand binding domain of the Fc $\gamma$ receptor with an

77 extracellular SNAP-tag that covalently binds a benzyl-guanine-labeled single-stranded 
78 DNA (ssDNA) [receptor DNA; Figure 1a; (Morrissey et al., 2018)]. The SNAP-tag was

79 then joined to the CD86 transmembrane domain followed by the intracellular signaling

80 domain of the FcR $\gamma$ chain (Nimmerjahn \& Ravetch, 2008). We expressed the DNA-

$81 \mathrm{CAR} \gamma$ in the macrophage-like cell line RAW264.7 and the monocyte-like cell line THP-1.

83 As an engulfment target, we used silica beads coated with a supported lipid bilayer to

84 mimic the surface of a target cell. The beads were functionalized with biotinylated ssDNA (ligand DNA) containing a sequence complementary to the receptor DNA via biotin-neutravidin interactions (Figure 1a). We used a ligand DNA strand that has 13

87 complementary base pairs to the receptor DNA, which we chose because the receptor88 ligand dwell time ( $24 \mathrm{sec}$ (Taylor et al., 2017)) was comparable to the dwell time of lgG-Fc $\gamma R$ interactions ( 30-150 sec (Li et al., 2007)).

91 To test whether this synthetic system can drive specific engulfment of ligand-

92 functionalized silica beads, we used confocal microscopy to measure the number of

93 beads that were engulfed by each cell (Figure 1b, c). The DNA-CAR $\gamma$ drove specific

94 engulfment of DNA-bound beads in both RAW264.7 and THP-1 cells (Figure 1c, S1).

95 The extent of engulfment was similar to IgG-coated beads, and the ligand density 96 required for robust phagocytosis was also comparable to IgG [Figure 1d, S1; (Bakalar et 97 al., 2018; Morrissey, Kern, \& Vale, 2020)]. As a control, we tested a variant of the DNA98 CAR that lacked the intracellular domain of the FcR $\gamma$ chain (DNA-CAR adhesion). Cells 99 expressing the DNA-CAR adhesion failed to induce engulfment of DNA-functionalized 100 beads (Figure 1c), demonstrating that this process depends upon the signaling domain 101 of the Fc $\gamma$ receptor. Together, these data show that the DNA-CAR $\gamma$ can drive 102 engulfment of targets in a ligand- and FcyR-specific manner.

103

104 DNA origami pegboards activate DNA-CAR $\gamma$ macrophages

106 DNA origami technology provides the ability to easily build three-dimensional objects 107 that present ssDNA oligonucleotides with defined nanometer-level spatial organization 108 (Hong, Zhang, Liu, \& Yan, 2017; Rothemund, 2006; Seeman, 2010; Shaw et al., 2019; 
109 Veneziano et al., 2020). We used DNA origami to manipulate the spatial distribution of

110 DNA-CAR $\gamma$ ligands in order to determine how nanoscale ligand spacing affects

111 engulfment. We used a recently developed two-tiered DNA origami pegboard that

112 encompasses a total of 72 ssDNA positions spaced $7 \mathrm{~nm}$ and $3.5 \mathrm{~nm}$ apart in the $\mathrm{x}$ and

113 y dimensions, respectively (Dong et al., 2021)(Figure 2a, S2). Each of the 72 ligand

114 positions can be manipulated independently, allowing for full control over the ligand at

115 each position (Figure S2). The DNA origami pegboard also contains fluorophores at

116 each of its four corners to allow for visualization, and 12 biotin-modified oligos on the

117 bottom half of the pegboard to attach it to a neutravidin-containing supported lipid

118 bilayer or glass coverslip (Figure 2a, b, S2).

120 To determine if the DNA origami pegboards could successfully activate signaling, we

121 first tested whether receptors were recruited to the origami pegboard in a ligand-

122 dependent manner. Using TIRF microscopy, we quantified the fluorescence intensity of

123 the recruited GFP-tagged DNA-CAR $\gamma$ receptor to origami pegboards presenting 0, 2, 4,

124 16, 36 or 72 ligands (Figure 2b-e). Using signal from the 72 ligand (72L) origami

125 pegboard as an internal intensity standard of brightness, and thus correcting for

126 differences in illumination between wells, we found that the average fluorescence

127 intensity correlated with the number of ligands presented by individual origami

128 pegboards (Figure 2d, e). In addition, we measured Syk recruitment to individual DNA

129 origami pegboards and found that Syk intensity also increased as a function of the

130 number of ligands present on each origami pegboard (Figure 2c, S3). These results

131 confirmed that our DNA origami system provides a platform that allows quantitative

132 receptor recruitment and the analysis of downstream signaling pathways.

134 Nanoscale clustering of ligand enhances phagocytosis

136 Fcy receptors cluster upon ligand binding, but the functional importance of such 137 clustering for phagocytosis has not been directly addressed, and whether a critical 138 density of receptor-ligand pairs is necessary to initiate Fc $\gamma R$ signaling is unclear 139 (Duchemin, Ernst, \& Anderson, 1994; Jaumouillé et al., 2014; Lin et al., 2016; Lopes et 
140 al., 2017; Sobota et al., 2005). To address these questions, we varied the size of ligand 141 clusters by designing DNA origami pegboards presenting 2-36 ligands. To ensure a

142 constant total number of ligands and origami pegboards on each bead, we mixed the 143 signaling origami pegboards with 0-ligand "blank" origami pegboards in appropriate 144 ratios (Figure 3a). We confirmed that the surface concentration of origami pegboards on 145 the beads was comparable using fluorescence microscopy (Figure S4). We found that 146 increasing the number of ligands per cluster increased engulfment, but that engulfment 147 plateaued at a cluster size of 8 ligands (Figure 3b). We confirmed that the observed 148 engulfment phenotype was both ligand, receptor, and Fc $\gamma \mathrm{R}$ signaling dependent (Figure $1493 c, d)$. Together, these data reveal that Fc $\gamma$ receptor clustering strongly enhances 150 engulfment, up to a cluster size of 8 ligands.

\section{Spatial organization of ligands in nanoclusters regulates engulfment}

154 Next, we examined whether distance between individual receptor-ligand molecules 155 within a signaling cluster impacts engulfment. For this experiment, we varied the 156 spacing of 4 ligands on the origami pegboard. The 4-ligand tight origami (4T) contains 4 157 ligands clustered at the center of the pegboard ( $7 \mathrm{~nm}$ by $3.5 \mathrm{~nm}$ square), the medium 158 origami (4M) has ligands spaced $21 \mathrm{~nm}$ by $17.5 \mathrm{~nm}$ apart, and the spread origami (4S) 159 has 4 ligands positioned at the four corners of the pegboard ( $35 \mathrm{~nm}$ by $38.5 \mathrm{~nm}$ square) 160 (Figure 4a). We found that the efficiency of macrophage engulfment was approximately 1612 -fold higher for the 4T functionalized beads when compared to the $4 \mathrm{M}$ or $4 \mathrm{~S}$ beads 162 (Figure 4a). We confirmed via fluorescence microscopy that the concentration of 163 origami pegboards on the surface was similar, and therefore ligand numbers on the 164 beads were similar (Figure S5). DNA CAR constructs that have the FcR $\gamma$ and ? chain 165 transmembrane domains in place of the CD86 transmembrane domain and human 166 THP-1 cells expressing the DNA-CAR $\gamma$ showed the same ligand spacing dependence 167 (Figure S5). Expression of the various DNA CARs at the cell cortex was comparable, 168 and engulfment of beads functionalized with both the 4T and the 4S origami platforms 169 was dependent on the Fc $\gamma \mathrm{R}$ signaling domain (Figure S5). Together, these results 170 demonstrate that macrophages preferentially engulf targets with tighter ligand clusters. 
172 Tightly spaced ligands could potentially increase phagocytosis by enhancing the avidity

173 of receptor-ligand interactions within each cluster. Such a hypothesis would predict that

174 tightly spaced ligands increase DNA-CAR $\gamma$-BFP occupancy at the phagocytic cup.

175 However, when we measured the total fluorescence intensity of receptors at the

176 phagocytic cup, we did not detect a difference in DNA-CAR $\gamma$-BFP recruitment to 4 T and

177 4S beads (Figure 6a, b). However, to eliminate any potential contribution of avidity, we

178 created $4 \mathrm{~T}$ and $4 \mathrm{~S}$ origami pegboards with very high-affinity 16mer DNA ligands that

179 are predicted to dissociate on a time scale of $>7 \mathrm{hr}$ (Taylor et al., 2017) (Figure 4b).

180 Using these 16mer high-affinity ligands, we found that $4 \mathrm{~T}$ origami beads were still

181 preferentially engulfed over $4 \mathrm{M}$ or $4 \mathrm{~S}$ origami beads (Figure 4b, S5). These results

182 suggest that an avidity effect is not the cause of the preferential engulfment of targets

183 having tightly spaced ligands.

\section{Tight ligand spacing enhances engulfment initiation and downstream signaling}

187 We next determined how ligand spacing affects the kinetics of engulfment. Using data 188 from live-cell imaging, we subdivided the engulfment process into three steps: bead 189 binding, engulfment initiation, and engulfment completion (Figure 5a, Supplemental 190 movie 1). To compare engulfment dynamics mediated by 4T and 4S origami pegboards

191 in the same experiment, we labeled each pegboard type with a different colored 192 fluorophore, functionalized a set of beads with each type of pegboard, and added both 193 bead types to macrophages at the same time (Figure 5b, Supplemental movie 2). 194 Macrophages interacted with beads functionalized with the 4T and 4S pegboards with 195 comparable frequency ( $46 \pm 7 \%$ total bead-cell contacts vs. $54 \pm 7 \%$ total bead-cell 196 contacts respectively). However, the probability of engulfment initiation was significantly 197 higher for the $4 \mathrm{~T}$ (95 $\pm 5 \%$ of bead contacts) versus $4 \mathrm{~S}$ (61 $\pm 9 \%$ of bead contacts) 198 beads, and the probability that initiation events resulted in successful completion of 199 engulfment was higher for $4 \mathrm{~T}$ (69 $\pm 9 \%$ of initiation events) versus $4 \mathrm{~S}$ (39 $\pm 11 \%$ of 200 initiation events) beads (Figure 5a). Initiation events that failed to induce successful 201 engulfment either stalled after progressing partially over the bead or retracted the 
202 extended membrane back to the base of the bead. In addition, for beads that were

203 engulfed, the time from contact to engulfment initiation was $\sim 300 \mathrm{sec}$ longer for beads

204 functionalized with 4S origami pegboards than beads containing 4T origami pegboards

205 (Figure 5c). However, once initiated, the time from initiation to completion of engulfment

206 did not differ significantly for beads coated with 4T or 4S origami (Figure 5d). Overall, 66

$207 \pm 8 \%$ of $4 \mathrm{~T}$ bead contacts resulted in successful engulfment compared to $24 \% \pm 8 \%$ for

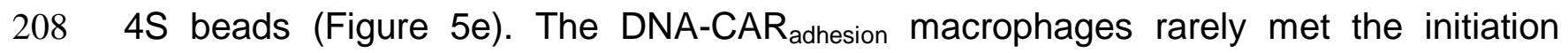

209 criteria, suggesting that active signaling from the $\mathrm{Fc} \gamma \mathrm{R}$ is required (Figure S6).

210 Together, these data reveal that tighter spacing between ligands within a cluster

211 enhances the probability and kinetics of initiating engulfment, as well as the overall

212 success frequency of completing engulfment, but does not affect the rate of phagosome

213 closure once initiated.

215 Tightly spaced ligands enhance receptor phosphorylation

217 We next determined how the 4T or 4S origami pegboards affect signaling downstream

218 of FcyR binding by measuring fold enrichment at the phagocytic cup compared to the

219 rest of the cortex of 1) a marker for receptor phosphorylation (the tandem SH2 domains

220 of Syk, (Bakalar et al., 2018; Morrissey et al., 2018)), 2) $\mathrm{PIP}_{3}$ (via recruitment of the $\mathrm{PIP}_{3}$

221 binding protein Akt-PH-GFP), and 3) filamentous actin (measured by rhodamine-

222 Phalloidin binding, Figure 6a, b). We found that 4T phagocytic cups recruited more

223 tSH2-Syk than the 4S beads, indicating an increase in receptor phosphorylation by

224 nano-clustered ligands. Generation of $\mathrm{PIP}_{3}$ and actin filaments at the phagocytic cup

225 also increased at 4T relative to 4S synapses (Figure 6b). This differential recruitment of

226 downstream signaling molecules to 4T versus 4S origami beads was most apparent in

227 early and mid-stage phagocytic cups; late-stage cups showed only a slightly significant

228 difference in tSH2-Syk recruitment and no significant differences in generation of $\mathrm{PIP}_{3}$

229 or actin filaments (Figure S7). Together, these data demonstrate that nanoscale ligand

230 spacing affects early downstream signaling events involved in phagocytic cup formation.

232 We next sought to understand why distributing ligands into tight clusters enhanced 
233 receptor phosphorylation and engulfment. One possibility is that the clustering of four

234 complete receptors is needed to drive segregation of the inhibitory phosphatase CD45

235 and allow sustained phosphorylation of the Fc $\gamma R$ Immune Receptor Tyrosine-based

236 Activation Motif (ITAM) (Bakalar et al., 2018; Freeman et al., 2016; Goodridge et al.,

237 2012; Schmid et al., 2016). Alternatively, the 4-ligand cluster may be needed to obtain a

238 critical intracellular concentration of Fc $\gamma$ R ITAM signaling domains. To test for the latter

239 possibility, we designed a synthetic receptor (DNA-CAR-4xy) that contains four repeats

240 of the intracellular domain of the DNA-CAR $\gamma$ connected by a GGSG linker between

241 each repeat (Figure 6c). We confirmed that this DNA-CAR-4x $\gamma$ receptor was more

242 potent in activating engulfment than an equivalent receptor (DNA-CAR-1 $x \gamma-3 x \Delta$ ITAM) in

243 which the 3 C-terminal ITAM domains were mutated to phenylalanines (Figure 6c, d).

244 Keeping the number of intracellular ITAMs constant, we compared the engulfment

245 efficiency mediated by two different receptors: 1) the DNA-CAR-4x $\gamma$ that interacted with

246 beads functionalized with 1-ligand origami, and 2) the DNA-CAR-1x $\gamma-3 \times \Delta$ ITAM that

247 interacted with beads coated with equivalent amounts of 4T origami (Figure 6c). While

248 the DNA-CAR-1 $x \gamma-3 \times \Delta$ ITAM-expressing macrophages engulfed 4T origami beads, the

249 DNA-CAR-4x $y$ macrophages failed to engulf the high-affinity 1-ligand origami beads

250 (Figure 6d, Figure S7). To ensure that all four ITAM domains on the DNA-CAR-4x $\gamma$ were 251 signaling competent, we designed two additional DNA CARs which placed the

252 functional ITAM at the second and fourth position (Figure S7). These receptors were 253 able to induce phagocytosis of $4 \mathrm{~T}$ origami beads, indicating that the DNA-CAR-4x $\gamma$

254 likely contains 4 functional ITAMs. Collectively, these results indicate that the tight 255 clustering of multiple receptors is necessary for engulfment and increasing the number 256 of intracellular signaling modules on a single receptor is not sufficient to surpass the 257 threshold for activation of engulfment.

\section{Discussion}

261 Macrophages integrate information from many FcyR-antibody interactions to 262 discriminate between highly opsonized targets and background signal from soluble 263 antibody or sparsely opsonized targets. How the macrophage integrates signals from 
264 multiple FcyR binding events to make an all-or-none engulfment response is not clear.

265 Here, we use DNA origami nanostructures to manipulate and assess how the nanoscale

266 spatial organization of receptor-ligand interactions modulates FcyR signaling and the

267 engulfment process. We found that tight ligand clustering increases the probability of

268 initiating phagocytosis by enhancing FcyR phosphorylation.

270 Phagocytosis requires IgG across the entire target surface to initiate local receptor 271 activation and to 'zipper' close the phagocytic cup (Freeman et al., 2016; Griffin et al., 272 1975). Consistent with this zipper model, incomplete opsonization of a target surface, or 273 micron-scale spaces between IgG patches, decreases engulfment (Freeman et al., 274 2016; Griffin et al., 1975). Initially suggested as an alternative to the zipper model, the 275 trigger model proposed that engulfment occurs once a threshold number of receptors 276 interact with IgG (Ben M'Barek et al., 2015; Griffin et al., 1975; Swanson \& Baer, 1995).

277 While this model has largely fallen out of favor, more recent studies have found that a 278 critical IgG threshold is needed to activate the final stages of phagocytosis (Y. Zhang et 279 al., 2010). Our data suggest that there may also be a nanoscale density-dependent 280 trigger for receptor phosphorylation and downstream signaling. Taken together, these 281 results suggest that both tight nanoscale $\operatorname{lgG}-\mathrm{Fc} \gamma \mathrm{R}$ clustering and a uniform distribution 282 of IgG across the target are needed to direct signaling to 'zipper' close the phagocytic 283 cup. Why might macrophages use this local density dependent trigger to dictate 284 engulfment responses? Macrophages constantly encounter background "eat me" 285 signals (Gonzalez-Quintela et al., 2008). This hyper-local density measurement may 286 buffer macrophages against background stimuli and weakly opsonized targets that are 287 unlikely to have adjacent bound antibodies, while still robustly detecting and efficiently 288 engulfing highly-opsonized targets.

290 Our findings are consistent with previous results demonstrating that Fc $\gamma \mathrm{R}$ crosslinking 291 correlates with increased ITAM phosphorylation (M. M. Huang et al., 1992; Kwiatkowska 292 \& Sobota, 2001; Lin et al., 2016; Sobota et al., 2005). While our data pinpoints a role for 293 ligand spacing in regulating receptor phosphorylation, it is possible that later steps in the 294 phagocytic signaling pathway are also directly affected by ligand spacing. The 
295 mechanism by which dense-ligand clustering promotes receptor phosphorylation

296 remains an open question, although our data rule out a couple of models. Specifically,

297 we demonstrate that nanoscale ligand clustering does not noticeably affect the amount

298 of ligand-bound receptor at the phagocytic cup, and that ligand spacing continues to

299 affect engulfment when avidity effects are diminished through the use of high affinity

300 receptor-ligands. Collectively, these data reveal that changes in receptor binding or

301 recruitment caused by increased avidity are unlikely to account for the increased

302 potency of clustered ligands. Our data also exclude the possibility that receptor

303 clustering simply increases the local intracellular concentration of FcyR signaling

304 domains, as arranging FcyR ITAMs in tandem did not have the same effect as clustering

305 multiple receptor-ligand interactions. However, it remains possible that the geometry of

306 the intracellular signaling domains could be important for activating or localizing

307 downstream signaling, and that tandem ITAMs on the same polypeptide cannot produce

308 the same engulfment signals as ITAMs on separate parallel polypeptides.

310 One possible model to explain the observed ligand-density dependence of signaling

311 involves the ordering of lipids around the Fc $\gamma$ receptor. Segregated liquid-ordered and

312 liquid-disordered membrane domains around immune receptor clusters have been

313 reported to promote receptor phosphorylation (Bag, Wagenknecht-Wiesner, Lee, Shi, \&

314 Holowka, 2020; Dinic, Riehl, Adler, \& Parmryd, 2015; Eggeling et al., 2009; Kabouridis,

315 2006; Simons \& Ikonen, 1997; Sohn, Tolar, Jin, \& Pierce, 2006; Stone, Shelby, Nńñez,

316 Wisser, \& Veatch, 2017). Fc $\gamma R$ clusters are associated with liquid-ordered domains

317 (Beekman, van der Linden, van de Winkel, \& Leusen, 2008; Katsumata et al., 2001;

318 Kwiatkowska \& Sobota, 2001). Liquid-ordered domains recruit Src family kinases, which

319 phosphorylate FcyRs, while liquid-disordered domains are enriched in the

320 transmembrane phosphatase CD45, which dephosphorylates FcyRs (Bag et al., 2020;

321 Sohn et al., 2006; Stone et al., 2017). Thus, lipid ordering could provide a mechanism

322 that leads to receptor activation if denser receptor-ligand clusters are more efficient in

323 nucleating or associating with ordered lipid domains. 
325 As an alternative model, a denser cluster of ligated receptors may enhance the steric 326 exclusion of the bulky transmembrane proteins like the phosphatases CD45 and CD148

327 (Bakalar et al., 2018; Goodridge et al., 2012; Zhu, Brdicka, Katsumoto, Lin, \& Weiss, 328 2008). CD45 is heavily glycosylated, making the extracellular domain $25-40 \mathrm{~nm}$ tall 329 (Davis \& van der Merwe, 2006; McCall, Shotton, \& Barclay, 1992; Woollett, Williams, \& 330 Shotton, 1985). Because of its size, CD45 is excluded from close cell-cell contacts, 331 such as those mediated by $\operatorname{lgG}-\mathrm{Fc} \gamma \mathrm{R}$, which have a dimension of $11.5 \mathrm{~nm}$ (Bakalar et 332 al., 2018; Burroughs et al., 2011; Carbone et al., 2017; Chung, Koo, \& Boxer, 2013; Lu, 333 Ellsworth, Hamacher, Oak, \& Sun, 2011; Schmid et al., 2016). IgG bound to antigens $334 \leq 10.5 \mathrm{~nm}$ from the target surface induces CD45 exclusion and engulfment (estimated 335 total intermembrane distance of $\leq 22 \mathrm{~nm}$ (Bakalar et al., 2018)). Our DNA origami 336 structure is estimated to generate similar intermembrane spacing, consisting of 337 hybridized receptor-ligand DNA ( 9.4 nm), the origami pegboard $(6 \mathrm{~nm})$ and neutravidin 338 (4 nm) (Rosano, Arosio, \& Bolognesi, 1999)]. A higher receptor-ligand density 339 constrains membrane shape fluctuations (Krobath, Rózycki, Lipowsky, \& Weikl, 2009, 340 2011; Rózycki, Lipowsky, \& Weikl, 2010), and this constraint may increase CD45 341 exclusion (Schmid et al., 2016). Both the lipid ordering and the steric exclusion models 342 predict at least a partial exclusion of the CD45 from the zone of the receptor cluster.

343 However, the dimension of the tight cluster in particular is very small (7 by $3.5 \mathrm{~nm}$ ) and 344 measurement of protein concentration at this level is currently not easily achieved, even 345 with super-resolution techniques. Overall, our results establish the molecular and spatial 346 parameters necessary for $\mathrm{Fc} \gamma \mathrm{R}$ activation and demonstrate that the spatial organization 347 of IgG-FcyR interactions alone can affect engulfment decisions.

349 How does the spacing requirements for Fc $\gamma \mathrm{R}$ nanoclusters compare to other signaling 350 systems? Engineered multivalent Fc oligomers revealed that IgE ligand geometry alters 351 Fce receptor signaling in mast cells (Sil, Lee, Luo, Holowka, \& Baird, 2007). DNA 352 origami nanoparticles and planar nanolithography arrays have previously examined 353 optimal inter-ligand distance for the T cell receptor, B cell receptor, NK cell receptor 354 CD16, death receptor Fas, and integrins (Arnold et al., 2004; Berger et al., 2020; Cai et 355 al., 2018; Deeg et al., 2013; Delcassian et al., 2013; Dong et al., 2021; Veneziano et al., 
356 2020). Some systems, like integrin-mediated cell adhesion, appear to have very 357 discrete threshold requirements for ligand spacing while others, like $\mathrm{T}$ cell activation, 358 appear to continuously improve with reduced intermolecular spacing(Arnold et al., 2004; 359 Cai et al., 2018). Our system may be more similar to the continuous improvement 360 observed in T cell activation, as our most spaced ligands $(36.5 \mathrm{~nm})$ are capable of 361 activating some phagocytosis, albeit not as potently as the 4T. Interestingly, as the 362 intermembrane distance between $\mathrm{T}$ cell and target increases, the requirement for tight 363 ligand spacing becomes more stringent (Cai et al., 2018). This suggests that IgG bound 364 to tall antigens may be more dependent on tight nanocluster spacing than short 365 antigens. Planar arrays have also been used to vary inter-cluster spacing, in addition to 366 inter-ligand spacing (Cai et al., 2018; Freeman et al., 2016). Examining the optimal 367 inter-cluster spacing during phagosome closure may be an interesting direction for 368 future studies.

370 Our study on the spatial requirements of FcyR activation could have implications for the 371 design of therapeutic antibodies or chimeric antigen receptors. Antibody therapies that 372 rely on FcyR engagement are used to treat cancer, autoimmune and neurodegenerative 373 diseases (Chao et al., 2010; Nimmerjahn \& Ravetch, 2005; Uchida et al., 2004; 374 Watanabe et al., 1999; Weiskopf et al., 2013; Weiskopf \& Weissman, 2015). 375 Multimerizing Fc domains, or targeting multiple antibodies to the same antigen may 376 increase antibody potency (X. Zhang et al., 2016). Interestingly, Rituximab, a successful 377 anti-CD20 therapy that potently induces ADCP, has two binding sites on its target 378 antigen (Zhao et al., 2020). Selecting clustered antigens, or pharmacologically inducing 379 antigen clustering may also increase antibody potency (Chew et al., 2020). These 380 results suggest that oligomerization may lead to more effective therapy; however, a 381 systematic study of the spatial parameters that affect FcyR activation has not been 382 undertaken (Bakalar et al., 2018). Our data suggest that antibody engineering strategies 383 that optimize spacing of multiple antibodies through leucine zippers, cysteine bonds, 384 DNA hybridization (Delcassian et al., 2013; Seifert et al., 2014; Sil, Lee, Luo, Holowka, 385 \& Baird, 2007) or multimeric scaffolds (Divine et al., 2020; Fallas et al., 2017; X. Huang 
bioRxiv preprint doi: https://doi.org/10.1101/2021.03.18.436011; this version posted March 18, 2021. The copyright holder for this preprint (which was not certified by peer review) is the author/funder, who has granted bioRxiv a license to display the preprint in perpetuity. It is made available under aCC-BY-NC-ND 4.0 International license.

386 et al., 2020; Ueda et al., 2020) could lead to stronger Fc $\gamma R$ activation and potentially

387 more effective therapies.

388

389 


\section{Figure Legends}

391

392

393

Figure 1: A DNA-based system for controlling engulfment

(A) Schematic shows the endogenous (left box) and DNA-based (middle and right boxes) engulfment systems. Engulfment via endogenous FcyRs (left box) is induced through anti-biotin IgG bound to 1-oleoyl-2-(12-biotinyl(aminododecanoyl))-sn-glycero-3phosphoethanolamine (biotin-PE) lipids incorporated into the bilayer surrounding the silica bead targets. Engulfment induced via the DNA-based system uses chimeric antigen receptors (CAR) expressed in the macrophage and biotinylated ligand DNA that is bound to the lipid bilayer surrounding the silica bead. The DNA-CARy (middle box) consists of a ssDNA (receptor DNA) covalently attached to an extracellular SNAP-tag fused to a CD86 transmembrane domain, the intracellular domain of the FcR $\gamma$ chain, and a fluorescent tag. The DNA-CAR adhesion (right box) is identical but lacks the signaling FcR $\gamma$ chain. (B) Example images depicting the engulfment assay. Silica beads were coated with a supported lipid bilayer (magenta) and functionalized with neutravidin and the indicated density of ligand DNA (Figure S1a). The functionalized beads were added to RAW264.7 macrophages expressing either the DNA-CAR $\gamma$ or the DNA$C A R_{\text {adhesion }}$ (green) and fixed after $45 \mathrm{~min}$. The average number of beads engulfed per macrophage was assessed by confocal microscopy. Scale bar denotes $5 \mu \mathrm{m}$ here and in all subsequent figures. Internalized beads are denoted with a white sphere in the merged images. (C) The number of beads engulfed per cell for DNA-CAR $\gamma$ (blue) or DNA-CAR adhesion (grey) macrophages was normalized to the maximum bead eating observed in each replicate. Dots and error bars denote the mean \pm SEM of three independent replicates ( $\mathrm{n} \geq 100$ cells analyzed per experiment). (D) DNA-CAR $\gamma$ expressing macrophages were incubated with bilayer-coated beads (grey) functionalized with anti-biotin IgG (magenta), neutravidin (black), or neutravidin and saturating amounts of ssDNA (blue). The average number of beads engulfed per cell was assessed. Full data representing the fraction of macrophages engulfing specific numbers of IgG or ssDNA beads is shown in figure S1. Each data point represents the mean of an independent experiment, denoted by symbol shape, and bars denote the 
421 mean \pm SEM. n.s. denotes $p>0.05,{ }^{*}$ indicates $p<0.05,{ }^{* *}$ indicates $p<0.005$ and ${ }^{* * * *}$

422 indicates $p<0.0001$ by a multiple t-test comparison corrected for multiple comparisons

423 using the Holm-Sidak method (C) or Student's T-test (D).

\section{Figure 2: DNA origami pegboard induces ligand dependent signaling}

426 (A) Schematic shows the DNA-origami pegboard used in this study (right) and the 427 components used to create it using a one-pot assembly method (left, figure S2). The top 428 of the two-tiered DNA origami pegboard has 72 positions spaced $7 \mathrm{~nm}$ and $3.5 \mathrm{~nm}$ apart 429 in the $x$ and $y$ dimensions, which can be modified to expose a single-stranded ligand 430 DNA (red) or no ligand (light blue). A fluorophore is attached at each corner of the 431 pegboard for visualization (pink). The bottom tier of the pegboard displays 12 biotin 432 molecules (yellow) used to attach the origami to neutravidin-coated surfaces. Full 433 representation of the DNA origami pegboard assembly is shown in figure S2. (B)

434 Schematic portraying the TIRF microscopy setup used to image THP-1 cells interacting 435 with origami pegboards functionalized to glass coverslips in (C) and (D) (left). On the 436 right is a zoomed-in side view of an origami pegboard functionalized to a biotin (yellow) 437 and neutravidin (grey) functionalized glass coverslip and interacting with a single DNA438 CAR $\gamma$ receptor. (C) TIRF microscopy images of THP-1 cells show that the DNA-CAR $\gamma$ 439 (BFP; $5^{\text {th }}$ panel; black in linescan), the receptor DNA bound to the DNA-CAR $\gamma$ (Cy5; $4^{\text {th }}$ 440 panel; green in linescan), and Syk (mNeonGreen; $3^{\text {rd }}$ panel; cyan in merge and 441 linescan) are recruited to individual 72 -ligand origami pegboards (Atto-647; $2^{\text {nd }}$ panel; 442 magenta in merge and linescan). Each diffraction limited magenta spot represents an 443 origami pegboard. The top panels show a single cell (outlined in yellow), and the bottom 444 insets (orange box in top image) show three origami pegboards at higher magnification. 445 The linescan (right, area denoted with a white arrow in merged inset) shows the 446 fluorescence intensity of each of these channels. Intensity was normalized so that 1 is 447 the highest observed intensity and 0 is background for each channel. (D) TIRF 448 microscopy images show DNA-CAR $\gamma$ expressing THP1s interacting with 72-ligand 449 origami pegboards (pink) and origami pegboards presenting the indicated number of 450 ligands (pegboards labeled in green). Left schematics represent origami pegboard 451 setups for each row of images where red dots denote the presence of a ligand DNA. 452 Middle images depict a single macrophage (outlined in yellow), and right images show 
453 the area indicated with an orange box on the left. Examples of DNA-CAR $\gamma$ -

454 mNeonGreen (grey) recruitment to individual origami pegboards is marked by pink (72L

455 origami pegboard) and green (origami pegboard with the indicated ligand number)

456 arrowheads (right). (E) Quantification of experiment shown in (D). Top graph shows the

457 DNA-CAR $\gamma$ intensity at the indicated origami pegboard type normalized to the average

458 DNA-CAR $\gamma$ intensity at 72L origami pegboards in the same well. Each dot represents

459 one origami pegboard and red lines denote the mean \pm SEM of pooled data from three 460 separate replicates. n.s. denotes $p>0.05$, * indicates $p<0.05$, and **** indicates

$461 \mathrm{p}<0.0001$ by an ordinary one-way ANOVA with Holm-Sidak's multiple comparison test.

462 A linear regression fit (bottom) of the average fluorescence intensities of each of the 463 origami pegboards suggests that the mean DNA-CAR $\gamma$ fluorescent intensities are 464 linearly proportional to the number of ligands per DNA origami pegboard. The black dots 465 represent the mean normalized DNA-CAR $\gamma$ intensity, the red line denotes the linear 466 regression fit, and the grey lines show the $95 \%$ confidence intervals.

Figure 3: Nanoscale clustering of ligand enhances phagocytosis

469 (A) Schematic showing an origami pegboard functionalized to a lipid bilayer 470 surrounding a silica bead (left) and the origami pegboard mixtures used to functionalize 471 the bilayer-coated silica beads for experiment quantified in (B) (right). Blue squares 472 represent origami pegboards with the indicated number of ligands (schematics below, 473 red dot denotes ligand DNA and light blue dot denotes no ligand) and grey squares 474 represent 0-ligand "blank" origami pegboards. Pie charts above describe the ratios of 475 ligand origami presenting pegboards to "blank" pegboards. (B) Beads were 476 functionalized with mixtures of origami pegboards containing the indicated ligand477 presenting origami pegboard and the 0-ligand "blank" origami pegboards in amounts 478 designated in $(\mathrm{A})$. The graph depicts the number of beads internalized per DNA-CAR $\gamma$ 479 expressing macrophage normalized to the maximum bead eating in that replicate. Each 480 dot represents an independent replicate ( $n \geq 100$ cells analyzed per experiment), 481 denoted by symbol shape, with red lines denoting mean \pm SEM. Data is normalized to 482 the maximum bead eating in each replicate. (C) Example image showing the DNA483 CAR $\gamma$ (green) drives engulfment of beads (bilayer labeled in magenta) functionalized 
484 with 4-ligand DNA origami pegboards. A cross section of the $z$ plane indicated in the 485 inset panel (white line, bottom), shows that beads are fully internalized. (D) Bilayer 486 coated silica beads were functionalized with neutravidin, neutravidin and DNA origami 487 pegboards presenting 0 DNA ligands, or neutravidin and 4-ligand DNA origami 488 pegboards. The graph depicts normalized bead eating per cell of the indicated bead

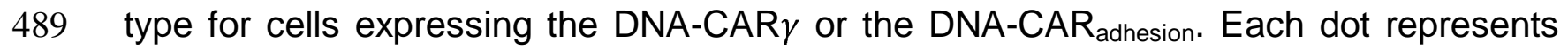
490 an independent replicate, denoted by symbol shape ( $n \geq 100$ cells analyzed per 491 experiment), with red lines denoting mean \pm SEM. The data are normalized to the 492 maximum bead eating in each replicate. * denotes $\mathrm{p}<0.05$, ** denotes $\mathrm{p}<0.005$, *** 493 denotes $p<0.0001$, and n.s. denotes $p>0.05$ in $(B)$ and $(D)$ as determined by an

494 Ordinary one-way ANOVA with Holm-Sidak's multiple comparison test.

496 Figure 4: Spatial arrangement of ligands within nanoclusters regulates 497 engulfment

498 (A) Schematics (top) depict 4-ligand origami pegboards presenting ligands at the 499 positions indicated in red. Beads were functionalized with 0-ligand 'blank' (grey) origami 500 pegboards, 4T (orange) origami pegboards, 4M (green) origami pegboards, or 4S 501 (cyan) origami pegboards at equal amounts and fed to DNA-CAR $\gamma$ expressing 502 macrophages. Representative confocal images (middle) depict bead (bilayer in 503 magenta) engulfment by macrophages (green). Internalized beads are denoted with a 504 white sphere. Quantification of the engulfment assay is shown in the graph below 505 depicting the number of beads engulfed per macrophage normalized to the maximum 506 observed eating in that replicate. (B) Schematics of the receptor DNA (blue) paired with 507 the medium affinity 13 base paired DNA-ligand (red) used in all previous experiments 508 including $(A)$ and the high affinity 16 base pair ligand-DNA (yellow) used for experiment 509 shown in graph below. Beads were functionalized with 0-ligand 'blank' (grey), high 510 affinity 4T (orange), high affinity 4M (green), or high affinity 4S (cyan) origami 511 pegboards and fed to DNA-CAR $\gamma$ expressing macrophages. Graph shows the number 512 of beads engulfed per macrophage normalized to the maximum observed eating in that 513 replicate. Each data point represents the mean of an independent experiment, shapes 514 denote data from the same replicate, and bars show the mean $\pm \operatorname{SEM}(A, B)$. * denotes 
$515 \mathrm{p}<0.05,^{* * *}$ denotes $\mathrm{p}<0.0005,{ }^{* * * *}$ denotes $\mathrm{p}<0.0001$, and n.s. denotes $\mathrm{p}>0.05$ as

516 determined by an Ordinary one-way ANOVA with Holm-Sidak's multiple comparison test

517 (A, B).

519 Figure 5: Nanoscale ligand clustering controls engulfment initiation

520 (A) Schematic portraying origami pegboards used to analyze the steps in the 521 engulfment process quantified in (C), (D), and (E). Bead binding is defined as the first 522 frame the macrophage contacts a bead; initiation is the first frame in which the 523 macrophage membrane has begun to extend around the bead, and completion is 524 defined as full internalization. The macrophage membrane was visualized using the 525 DNA CAR $\gamma$, which was present throughout the cell cortex. The \% of beads that progress 526 to the next stage of engulfment (\% success) is indicated for 4T (orange, origami labeled 527 with Atto550N) and 4S (cyan, origami labeled with Atto647N) beads. **** denotes $528 \mathrm{p}<0.0001$ as determined by Fischer's exact test. (B) Still images from a confocal 529 microscopy timelapse showing the macrophage (green) interacting with both the 4T 530 origami pegboard functionalized beads (orange) and the 4S origami pegboard 531 functionalized beads (cyan), but preferentially engulfing the 4T origami pegboard 532 functionalized beads. In the bottom panel (DNA-CAR $\gamma$ channel), engulfed beads have 533 been indicated by a sphere colored to match its corresponding origami type. (C) Graph 534 depicts quantification of the time from bead contact to engulfment initiation for all beads 535 that were successfully engulfed. Each dot represents one bead with red lines denoting 536 mean \pm SEM. (D) Graph depicts the time from engulfment initiation to completion. Each 537 dot represents one bead with red lines denoting mean \pm SEM. (E) Graph shows the 538 fraction of contacted 4T and 4S beads engulfed (orange and cyan, respectively) by the 539 macrophages. Data represent quantification from 4 independent experiments, denoted 540 by symbol shape, and bars denote the mean \pm SEM. n.s. denotes $p>0.05$ and ** 541 indicates $\mathrm{p}<0.005$ by Student's T-test comparing the 4T and 4S functionalized beads 542 (C-E). 
545 (A) Beads were functionalized with 4T (orange) or 4S (cyan) origami pegboards at equal 546 amounts, added to macrophages expressing the DNA-CAR $\gamma$ (magenta) and the 547 indicated signaling reporter protein (green; greyscale on top). Phagocytic synapses 548 were imaged via confocal microscopy. Asterisks indicate whether a 4T (orange) or a 4S 549 (cyan) bead is at the indicated phagocytic synapse in the upper panel. (B) Schematic 550 (left) depicts the areas measured from images shown in $(A)$ to quantify the fluorescence 551 intensity (yellow outlines). Each phagocytic synapse measurement was normalized to 552 the fluorescence intensity of the cell cortex at the same z-plane. Graphs (right) depict 553 the ratio of fluorescence at $4 \mathrm{~T}$ or $4 \mathrm{~S}$ functionalized bead synapses to the cortex for the 554 indicated reporter. Each dot represents one bead with red lines denoting mean \pm SEM. 555 (C) Schematic portraying the CAR constructs and origami used in the experiment 556 quantified in (D). The DNA-CAR-4xy construct (left) consists of four repeats of the 557 intracellular domain of the DNA-CAR $\gamma$ connected by a GGSG linker. The DNA-CAR$5581 \times \gamma-3 \times \Delta$ ITAM (right) is identical to the DNA-CAR-4x $\gamma$ except that the tyrosines 559 composing the ITAM domains (purple circles) are mutated to phenylalanines in the 560 three C-terminal repeats (grey). Cells expressing either of these constructs were fed 561 beads functionalized with either high affinity 1-ligand origami pegboards (left), high 562 affinity 4T origami pegboards (right), or 0 ligand "blank" origami pegboards (not shown), 563 and engulfment was assessed after $45 \mathrm{~min}$. (D) Graph shows the number of beads 564 engulfed per macrophage normalized to the maximum observed eating in that replicate.

565 Each data point represents the mean from an independent experiment, denoted by 566 symbol shape, and bars denote the mean \pm SEM. Blue points represent a condition 567 where 16 ITAMs are available per origami, orange points represent conditions where 4 568 ITAMs are available per origami, purple points represent a condition where 1 ITAM is 569 available per origami, and grey points represent conditions where no ITAM is available. 570 n.s. denotes $p>0.05$, *** denotes $p<0.0005$, and ${ }^{* * *}$ denotes $p<0.00005$ as determined

571 by the Student's T-test (B) or an Ordinary one-way ANOVA with Holm-Sidak's multiple 572 comparison test (D). 


\section{Supplemental Figure Legends}

577 Figure S1, related to Figure 1: DNA-based engulfment system reflects 578 endogenous engulfment

579 (A) Graph depicts the calibration used to determine the surface density of ssDNA on

580 beads used in Figure 1b, c. The intensity of Alexa Fluor 647 fluorescent bead standards

581 (black dots) was measured, and a simple linear regression (red line) was fit to the data.

582 The fluorescence intensity of Alexa Fluor 647-ssDNA coated beads (blue dots) was

583 measured, and the surface density was interpolated using the regression determined

584 from the fluorescent bead standards. The concentration of ssDNA used for each bead

585 coupling condition is indicated next to the blue points on the graph. (B) Macrophages

586 expressing the DNA-CAR $\gamma$ (blue) or the DNA-CAR adhesion (grey) engulfed similar

587 distributions of $\mathrm{lgG}$ functionalized beads. Data is pooled from two independent

588 replicates. (C) Graph depicts the fraction of macrophages engulfing the indicated

589 number of IgG (magenta) or ssDNA (blue) beads from data pooled from the three

590 independent replicates presented in Figure 1d. (D) Graph shows the average number of

591 Neutravidin (black), ligand-DNA (blue), or lgG (magenta) functionalized beads engulfed

592 by the monocyte-like cell line THP1. Lines denote the mean engulfment from each

593 independent replicate and bars denote \pm SEM. $P$ values were calculated using the

594 Mann-Whitney test $(B, C)$ and n.s. denotes $p>0.05$ as determined by the Student's T-

595 test (D).

597 Figure S2, related to Figure 2: Design and Assembly of Nanoscale Ligand598 Patterning Pegboard built from DNA origami.

599 (A) 2D schematic of origami scaffold and staples. The p8064 ssDNA scaffold is 600 combined with 160 ssDNA staples that form the chassis, biotin-modified surface 601 anchors, and ATTO647N-labeled dyes, plus a combination of 72 ligand-patterning 602 staples. We used three variants of the ligand-patterning staples: "-ligand" that lacks a 3' 603 single-stranded overhang and terminates flush with the pegboard surface, and a 604 "medium-affinity" (red) and "high-affinity" (yellow) that form 13-bp and 16-bp duplexes 605 with the DNA-CAR receptors, respectively. Assembly is performed by thermal annealing 
606 in a one-pot reaction. (B) Cadnano strand diagram for the pegboard with 72 medium-

607 affinity ligands included. (C) Fourteen pegboard configurations were used in this study.

608 Configurations are labeled by ligand count, spacing, and ligand affinity, and the 609 corresponding plate wells used in each assembly are shown.

611 Figure S3, related to Figure 2: Syk intensity increases with ligand number in 612 origami cluster

613 (A) TIRF microscopy images showing DNA-CAR $\gamma$-mNeonGreen and Syk-BFP

614 expressing THP1s interacting with 72-ligand origami pegboards (pink) and origami 615 pegboards presenting the indicated number of ligands (green) plated together on a 616 glass surface (schematics shown on the left). Middle images depict a single 617 macrophage, and right images show the area indicated with a yellow box on the left. 618 Examples of Syk-BFP (grey) recruitment to individual origami pegboards is marked by 619 pink (72L origami) and green (indicated ligand number origami) arrowheads (right). (B)

620 Top graph shows the Syk intensity at each indicated origami pegboard type normalized 621 to the average Syk intensity at 72L origami pegboards for each condition. Each dot 622 represents the normalized Syk intensity at one origami and red lines denote the mean \pm 623 SEM of pooled data from three separate replicates. At ligand numbers fewer than 16, 624 we did not detect Syk enrichment over background fluorescence of cytosolic Syk. A 625 linear regression fit (bottom) of the average Syk fluorescence intensity at each origami 626 pegboard type suggests that the mean Syk recruitment is linearly proportional to the 627 number of ligands per DNA origami. n.s. denotes $p>0.05$ and **** indicates $p<0.0001$ 628 by an ordinary one-way ANOVA with Holm-Sidak's multiple comparison test.

630 Figure S4, related to Figure 3: Origami intensity on beads is comparable across 631 conditions

633 (A) Graph shows the average Atto647N fluorescence intensity from the beads used in 634 Figure 3a, b measured using confocal microscopy. Each dot represents an independent 635 replicate ( $\mathrm{n} \geq 100$ cells analyzed per experiment), denoted by symbol shape, with red 
636 lines denoting mean \pm SEM. n.s. denotes $p>0.05$ as determined by an Ordinary oneway ANOVA with Holm-Sidak's multiple comparison test.

Figure S5, related to Figure 4: Ligand clustering enhances engulfment in RAW macrophages expressing DNA CARs with endogenous Fc $\gamma R$ transmembrane domains and in THP1s

(A) Graph shows the average Atto647N fluorescence intensity from the beads used in

644 Figure 4a measured using confocal microscopy. (B) Beads were functionalized with the

645 indicated ligand-presenting origami pegboards in amounts calculated to equalize the 646 total number of origami pegboards and ligands across conditions. Schematics (left) 647 depict the origami utilized, where the positions presenting a ligand (red dots) and the 648 positions not occupied by a ligand (light blue) are indicated. Graph (right) depicts the 649 average number of the indicated type of beads internalized per DNA-CAR $\gamma$-expressing 650 THP1, normalized to the maximum bead eating in that replicate. (C) Graph shows the 651 average Atto647N647 fluorescence intensity from the beads used in Figure 4b 652 measured using confocal microscopy. (D) Schematics below graph depict the DNA CAR 653 constructs designed with varying transmembrane domains. Beads were functionalized 654 with 4T origami pegboards (orange), 4S origami pegboards (cyan), or 0-ligand 'blank' 655 origami pegboards (grey) and fed to macrophages expressing the DNA CAR receptor 656 depicted below each section of the graph. Graph depicts the number of beads engulfed 657 per macrophage normalized to the maximum observed eating in that replicate. (E) 658 Graph shows the average Atto647N fluorescence intensity from the beads used in (D) 659 measured using confocal microscopy. (F) DNA CAR receptors used in (D) are 660 expressed and trafficked to the membrane at similar levels. Fluorescent intensity at the 661 cell cortex of the DNA CAR-infected macrophage was quantified using the mean 662 intensity of a 2 pixel width linescan at the cell membrane, with the mean intensity of a 663 linescan immediately adjacent to the cell subtracted for local background. The 664 fluorescence intensity was normalized to the average intensity of the DNA CAR adhesion $_{\text {in }}$ 665 each experiment. Each dot represents an individual cell and data is pooled from 3 666 independent experiments, with red lines denoting mean \pm SEM. n.s. denotes $p>0.05$, * 
667 denotes $p<0.05,{ }^{* *}$ denotes $p<0.005,{ }^{* * *}$ denotes $p<0.0005$, and ${ }^{* * * *}$ indicates $p<0.0001$

668 as determined by an Ordinary one-way ANOVA with Holm-Sidak's multiple comparison 669 test $(\mathrm{A}-\mathrm{F})$.

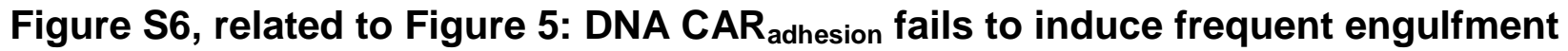

(A) The average number of 4T origami pegboard-functionalized beads contacting (grey),

675 in the initiation stage of engulfment (blue), or fully engulfed (green) by macrophages

676 expressing either the DNA CAR ${ }_{\text {adhesion }}$ or the DNA CAR $\gamma$ were quantified from fixed still

677 images after 45 minutes of engulfment. 125 beads in contact with DNA CAR expressing

678 macrophages were analyzed in 3 independent replicates. Bars represent the average

679 number of beads identified at each stage and black lines denote \pm SEM between 680 replicates. n.s. denotes $\mathrm{p}>0.05$ and * denotes $\mathrm{p}<0.05$ as determined by an unpaired t681 test with Holm-Sidak's multiple comparison test.

683 Figure S7, related to Figure 6: Differential recruitment of downstream signaling molecules is greater at early and mid-stage phagocytic cups

(A) Data from experiment shown in Figure $6 \mathrm{~b}$ is separated by early (macrophage membrane extends across $<30 \%$ of the bead, left), mid (macrophage membrane extends across $30-70 \%$ of the bead, middle), and late (macrophage membrane extends across $>70 \%$ of the bead, right) stage phagocytic cups. Graphs depict the ratio of fluorescence intensity at $4 \mathrm{~T}$ or $4 \mathrm{~S}$ functionalized bead synapses compared to the

691 cortex. Each dot represents one bead with red lines denoting mean \pm SEM. n.s. denotes $692 p>0.05$, * denotes $p<0.05$, ${ }^{* * *}$ denotes $p<0.0005$, and ${ }^{* * *}$ denotes $p<0.00005$ by the

693 Student's T-test. (B) Graph shows the average Atto647N fluorescence intensity from the 694 beads used in Figure 6d measured using confocal microscopy. (C) Schematics depict 695 the DNA-CAR-4xy constructs used for experiment quantified in (D). (D) DNA CAR 696 constructs shown in (C) were expressed in RAW macrophages and fed beads 697 functionalized with $4 \mathrm{~T}$ high affinity origami pegboards, 1 ligand high affinity origami 
698 pegboards, or 0 ligand origami pegboards. Graph depicts the number of beads engulfed 699 per macrophage normalized to the maximum observed eating in that replicate. Each 700 data point represents the mean from an independent experiment, denoted by symbol 701 shape, and bars denote the mean \pm SEM. Blue points represent a condition where 16 702 ITAMs are available per origami, orange points represent conditions where 4 ITAMs are 703 available per origami, purple points represent a condition where 1 ITAM is available per

704 origami, and grey points represent conditions where no ITAM is available. (E) Graph 705 shows the average Atto647N fluorescence intensity from the beads used in (D) 706 measured using confocal microscopy. (F) DNA CAR receptors used in (D) are 707 expressed and trafficked to the membrane at similar levels. Fluorescent intensity at the 708 cell cortex of the DNA CAR infected macrophage was quantified using the mean 709 intensity of a 2 pixel width linescan at the cell membrane, with the mean intensity of a 710 linescan immediately adjacent to the cell subtracted for local background. The 711 fluorescence intensity was normalized to the average intensity of the DNA-CAR-4x $\gamma$ in 712 each experiment. Each dot represents an individual cell and data is pooled from 3 713 independent experiments, with red lines denoting mean \pm SEM. n.s. denotes $p>0.05$ 714 and $^{* * *}$ indicates $\mathrm{p}<0.0001$ as determined by an Ordinary one-way ANOVA with Holm715 Sidak's multiple comparison test (B,D-F).

717 Supplemental movie 1: The engulfment program broken into three steps, bead 718 binding, engulfment initiation, and engulfment completion.

719 A macrophage infected with the DNA-CAR $\gamma$ (green) engulfs a 5 um silica bead coated

720 in a supported lipid bilayer (magenta) and functionalized with 4T origami pegboards.

721 The movie is a maximum intensity projection of z-planes and depicts the bead binding,

722 initiation, and completion steps of the engulfment process. Time is indicated at the top 723 left and scale bar denotes 5 um.

725 Supplemental movie 2: DNA CAR $\gamma$ macrophages preferentially engulf beads 726 functionalized with tightly spaced ligands.

727 A DNA-CAR $\gamma$ expressing macrophage (green) interacts with 4T origami pegboard 728 functionalized beads (orange) and 4S origami pegboard functionalized beads (cyan) 
729 that were added simultaneously and in equal amounts to the well of cells. The 730 macrophage engulfs only 4T origami pegboard functionalized beads. The movie is a

731 maximum intensity projection of z-planes acquired every 20 secs for 28 min. Time is 732 indicated at the top left. 


\section{Methods}

734

735

736

737

738

739

740

741

742

743

744

745

746

747

748

\section{9}

750

751

752

753

754

755

756

757

758

759

760

761

762

763

764

\section{Cell culture}

RAW264.7 macrophages were purchased from the ATCC and cultured in DMEM (Gibco, Catalog \#11965-092) supplemented with 1x Penicillin-Streptomycin-LGlutamine (Corning, Catalog \#30-009 Cl), $1 \mathrm{mM}$ sodium pyruvate (Gibco, Catalog \#11360-070) and 10\% heat-inactivated fetal bovine serum (Atlanta Biologicals, Catalog \#S11150H). THP1 cells were also purchased from the ATCC and cultured in RPMI 1640 Medium (Gibco, Catalog \#11875-093) supplemented with 1x Pen-Strep-Glutamine and $10 \%$ heat-inactivated fetal bovine serum. All cells were certified mycoplasma-free and discarded after 20 passages to minimize variation.

\section{Constructs and antibodies}

All relevant information can be found in the key resources table, including detailed descriptions of the amino acid sequences for all constructs.

\section{Lentivirus production and infection}

Lentiviral infection was used to express constructs described in the key resources table in either RAW264.7 or THP1 cells. Lentivirus was produced by HEK293T cells or Lenti$X$ 293T cells (Takara Biosciences, Catalog \#632180) transfected with pMD2.G (a gift from Didier Tronon, Addgene plasmid \# 12259 containing the VSV-G envelope protein), pCMV-dR8.91 (since replaced by second generation compatible pCMV-dR8.2, Addgene plasmid \#8455), and a lentiviral backbone vector containing the construct of interest (derived from pHRSIN-CSGW, see key resource table) using lipofectamine LTX (Invitrogen, Catalog \# 15338-100). The HEK293T media was harvested 60-72 hr posttransfection, filtered through a $0.45 \mu \mathrm{m}$ filter, and concentrated using Lenti-X (Takara Biosciences, Catalog \#631232) via the standard protocol. Concentrated virus was added directly to the cells and the plate was centrifuged at $2200 \mathrm{xg}$ for $45 \mathrm{~min}$ at $37^{\circ} \mathrm{C}$. Cells were analyzed a minimum of $60 \mathrm{hr}$ later. Cells infected with more than one viral construct were FACs sorted (Sony SH800) before use to enrich for double infected cells. 


\section{DNA origami preparation}

766 The DNA origami pegboard utilized for all experiments was generated as described in 767 figure S2. The p8064 DNA scaffold was purchased from IDT (Catalog \# 1081314). All 768 unmodified oligonucleotides utilized for the origami were purchased from IDT in 96 well 769 plates with standard desalting purification and resuspension at $100 \mu \mathrm{M}$ in water. 770 Fluorophore and biotin conjugated oligonucleotides were also purchased from IDT 771 (HPLC purification). All oligonucleotide sequences are listed in table 1, the assembly is 772 schematized in figure S2, and the Cadnano strand diagram for the pegboard with 72 773 medium-affinity ligands is included in S2. Core staple oligonucleotides (200 nM) (plates

7741 and 2), ligand oligonucleotides (200nM) (plates 3-L, 3MA, and 3HA), biotinylated 775 oligonucleotides (200nM), DNA scaffold (20 nM final concentration), and fluorophore776 labeled oligonucleotides ( $200 \mathrm{nM}$ final concentration) were mixed in $1 \mathrm{x}$ folding buffer (5 $777 \mathrm{mM}$ Tris $\mathrm{pH}$ 8.0, $1 \mathrm{mM}$ EDTA, $5 \mathrm{mM} \mathrm{NaCl}, 20 \mathrm{mM} \mathrm{MgCl}$ ). Origami folding reaction was 778 performed in a PCR thermocycler (Bio-Rad MJ Research PTC-240 Tetrad), with initial 779 denaturation at $65^{\circ} \mathrm{C}$ for $15 \mathrm{~min}$ followed by cooling from $60^{\circ} \mathrm{C}$ to $40^{\circ} \mathrm{C}$ with a decrease 780 of $1^{\circ} \mathrm{C}$ per $\mathrm{hr}$. To purify excess oligonucleotides from fully folded DNA origami, the DNA 781 folding reaction was mixed with an equal volume of PEG precipitation buffer (15\% (w/v) 782 PEG-8000, $5 \mathrm{mM}$ Tris-Base $\mathrm{pH}$ 8.0, $1 \mathrm{mM}$ EDTA, $500 \mathrm{mM} \mathrm{NaCl}, 20 \mathrm{mM} \mathrm{MgCl}$ ) and 783 centrifuged at $16,000 \times$ rcf for $25 \mathrm{~min}$ at room temperature. The supernatant was 784 removed, and the pellet was resuspended in 1x folding buffer. PEG purification was 785 repeated a second time and the final pellet was resuspended at the desired 786 concentration in $1 \mathrm{x}$ folding buffer and stored at $4^{\circ} \mathrm{C}$.

\section{Preparation of benzylguanine-conjugated DNA oligonucleotides}

789 5'-amine modified (5AmMC6) DNA oligonucleotides were ordered from IDT and diluted 790 in $0.15 \mathrm{M} \mathrm{HEPES} \mathrm{pH} 8.5$ to a final concentration of $2 \mathrm{mM}$. N-hydroxysuccinimide ester 791 (BG-GLA-NHS) functionalized benzylguanine was purchased from NEB (Cat \#S9151S) 792 and freshly reconstituted in DMSO to a final concentration of $83 \mathrm{mM}$. To functionalize 793 the oligonucleotides with benzylguanine, the two solutions were mixed so that the molar 794 ratio of oligonucleotide-amine:benzylguanine-NHS is $1: 50$, and the final concentration of 795 HEPES is between $50 \mathrm{mM}$ and $100 \mathrm{mM}$. The reaction was left on a rotator overnight at 
796 room temperature. To remove excess benzylguanine-NHS ester, the reaction product

797 was purified the next day with illustra NAP-5 Columns (Cytiva, Cat \#17085301), using

$798 \mathrm{H}_{2} \mathrm{O}$ for elution. The molar concentration of the benzylguanine conjugated

799 oligonucleotides was determined by measuring the absorbance of the purified reaction

800 at $260 \mathrm{~nm}$ with a Nanodrop. This reaction was further condensed with the Savant

801 SpeedVac DNA 130 Integrated Vacuum Concentrator System, resuspended in water to

802 a final concentration of $100 \mu \mathrm{M}$, aliquoted, and stored at $-20^{\circ} \mathrm{C}$ until use.

804 Functionalization of glass surface with DNA origami

805 96-well glass bottom MatriPlates were purchased from Brooks (Catalog \# MGB096-1-2-

806 LG-L). Before use, plates were incubated in 5\% (v/v) Hellmanex III solution (Z805939-

807 1EA; Sigma) overnight, washed extensively with Milli-Q water, dried under the flow of

808 nitrogen gas, and covered with sealing tape (ThermoFisher, Cat \# 15036). Wells used

809 for experiment were unsealed, incubated with $200 \mu \mathrm{L}$ of Biotin-BSA (ThermoFisher, Cat

810 \# 29130) at $0.5 \mathrm{mg} / \mathrm{mL}$ in PBS pH 7.4 at RT for $2 \mathrm{hr}$-overnight. Wells were washed 6x

811 with PBS pH 7.4 to remove excess BSA and incubated for $30 \mathrm{~min}$ at room temperature

812 with $100 \mu \mathrm{L}$ neutravidin at $250 \mu \mathrm{g} / \mathrm{mL}$ in PBS pH 7.4 for origami quantification and 50

$813 \mu \mathrm{g} / \mathrm{mL}$ for cellular experiments. Wells were again washed $6 \mathrm{x}$ with PBS $\mathrm{pH} 7.4$

814 supplemented with $20 \mathrm{mM} \mathrm{MgCl}_{2}$ and incubated for 1-2 hr with the desired amount of

815 DNA origami diluted in PBS pH 7.4 with $20 \mathrm{mM} \mathrm{MgCl}_{2}$ and $0.1 \% \mathrm{BSA}$

817 DNA origami quantification

8185 wells of a 96-well glass bottom MatriPlate per origami reaction were prepared as 819 described in 'Functionalization of glass surface with DNA origami'. The purified DNA 820 origami reaction was serially diluted into $\mathrm{PBS} \mathrm{pH} 7.4$ with $20 \mathrm{mM} \mathrm{MgCl}_{2}$ and $0.1 \% \mathrm{BSA}$ 821 and 5 different concentrations were plated and incubated for $1.5 \mathrm{hr}$ before washing $5 \mathrm{x}$ 822 with PBS pH 7.4 with $20 \mathrm{mM} \mathrm{MgCl}_{2}$ and $0.1 \%$ BSA. Fluorescent TIRF images were 823 acquired in the channel with which the origami was labeled. 100 sites per well were 824 imaged using the High Content Screening (HCS) Site Generator plugin in uManager 825 (Stuurman, Edelstein, Amodaj, Hoover, \& Vale, 2010). The number of individual DNA 826 origami per um $^{2}$ in each well were quantified using the Spot Counter plugin in Fiji. This 
827 was repeated for all concentrations of origami plated. The final concentration of the

828 origami reaction was measured as number of origami/ $\mu^{2}$ and was calculated from a

829 linear fit including all concentrations in which individual origami could be identified by

830 the plugin.

\section{TIRF imaging}

833 96-well glass bottom MatriPlates were functionalized with DNA origami as described 834 and then washed into engulfment imaging media (20 mM Hepes pH 7.4, $135 \mathrm{mM} \mathrm{NaCl}$, $8354 \mathrm{mM} \mathrm{KCl}, 1 \mathrm{mM} \mathrm{CaCl}_{2}, 10 \mathrm{mM}$ glucose) containing $20 \mathrm{mM} \mathrm{MgCl}_{2} . \sim 100,000$ dual

836 infected mNeonGreen-DNA-CAR $\gamma$ and BFP-Syk THP1 cells per well were pelleted via 837 centrifugation, washed into engulfment imaging media, re-pelleted, and resuspended 838 into $50 \mu \mathrm{L}$ of engulfment imaging media. $1 \mathrm{uL}$ of $100 \mu \mathrm{M}$ benzylguanine-labeled receptor 839 DNA stock was added per $\sim 50,000$ cells pelleted, and the cell-DNA mixture was 840 incubated at room temperature for $15 \mathrm{~min}$. Cells were subsequently washed twice via 841 centrifugation with $10 \mathrm{~mL}$ of imaging buffer to remove excess benzylguanine labeled 842 DNA and resuspended in $200 \mu \mathrm{L}$ per 100,000 cells of imaging buffer containing $20 \mathrm{mM}$ $843 \mathrm{MgCl}_{2}$. Cells were then immediately added to each well and imaged. Data was only 844 collected from a central ROI in the TIRF field. The origami fluorescent intensities along 845 the $x$ and $y$ axis were plotted to ensure there was no drop off in signal and thus no 846 uniformity of illumination.

\section{Quantification of receptor and Syk recruitment to individual origami}

849 Cells that expressed both the mNeonGreen tagged DNA-CAR $\gamma$ receptor and the BFP-

850 tagged Syk and had interactions with the 72-ligand origami were chosen for analysis in 851 Fiji. An ROI was drawn around the perimeter of the cell-glass surface interaction, which 852 was determined by the presence of receptor fluorescence. The 'Spot Intensity in All 853 Channel' plugin in Fiji was used to identify individual origami pegboards, measure 854 fluorescence intensity of the DNA-CAR $\gamma$ receptor and Syk at each origami pegboard, 855 and subtract local background fluorescence. The intensity at each origami pegboard 856 was normalized to the average intensity measured at 72-ligand origami pegboards in 857 each well. 


\section{Supported lipid bilayer coated silica bead preparation}

860 Chloroform-suspended lipids were mixed in the following molar ratios: 96.8\% POPC

861 (Avanti, Catalog \# 850457), 2.5\% biotinyl cap PE (Avanti, Catalog \# 870273), 0.5\%

862 PEG5000-PE (Avanti, Catalog \# 880230, and 0.2\% atto390-DOPE (ATTO-TEC GmbH,

863 Catalog \# AD 390-161) for labeled lipid bilayers, or 97\% POPC, 2.5\% biotinyl cap PE,

864 and 0.5\% PEG5000-PE for unlabeled lipid bilayers. The lipid mixes were dried under

865 argon gas and desiccated overnight to remove chloroform. The dried lipids were

866 resuspended in $1 \mathrm{~mL}$ PBS, pH 7.2 (Gibco, Catalog \# 20012050) and stored under argon

867 gas. Lipids were formed into small unilamellar vesicles via $\geq 30$ rounds of freeze-thaws

868 and cleared via ultracentrifugation (TLA120.1 rotor, 35,000 rpm / 53,227 x g, $35 \mathrm{~min}$,

$8694^{\circ} \mathrm{C}$ ). Lipids were stored at $4^{\circ} \mathrm{C}$ under argon gas in an eppendorf tube for up to two

870 weeks. To form bilayers on beads, $8.6 \times 10^{8}$ silica beads with a $4.89 \mu \mathrm{m}$ diameter $(10 \mu \mathrm{l}$

871 of $10 \%$ solids, Bangs Labs, Catalog \# SS05N) were washed 2x with water followed by

872 2x with PBS by spinning at 300rcf and decanting. Beads were then mixed with $1 \mathrm{mM}$

873 SUVs in PBS, vortexed for $10 \mathrm{~s}$ at medium speed, covered in foil, and incubated in an

874 end-over-end rotator at room temperature for 0.5-2 hr to allow bilayers to form over the

875 beads. The beads were then washed $3 x$ in PBS to remove excess SUVs, and

876 resuspended in $100 \mathrm{uL}$ of $0.2 \%$ casein (Sigma, catalog \# C5890) in PBS for 15 min at

877 room temperature to block nonspecific binding. Neutravidin (Thermo, Catalog \# 31000)

878 was added to the beads at a final concentration of $1 \mathrm{ug} / \mathrm{ml}$ for $20-30 \mathrm{minutes}$, and the

879 beads were subsequently washed $3 x$ in PBS with $0.2 \%$ casein and $20 \mathrm{mM} \mathrm{MgCl}_{2}$ to

880 remove unbound neutravidin. The indicated amounts of biotinylated ssDNA or

881 saturating amounts of DNA origami pegboards were added to the beads and incubated

882 for $1 \mathrm{hr}$ at room temperature with end-over-end mixing to allow for coupling. Beads were

883 washed 2 times and resuspended in $100 \mathrm{uL}$ PBS with $0.2 \%$ casein and $20 \mathrm{mM} \mathrm{MgCl} 2$ to

884 remove uncoupled origami pegboards or ssDNA. When functionalizing SUV-coated

885 beads with anti-biotin AlexaFluor647-IgG (Jackson ImmunoResearch Laboratories

886 Catalog \# 200-602-211, Lot \# 137445), the IgG was added to the beads at 1uM

887 immediately following the casein blocking step, and beads were incubated for $1 \mathrm{hr}$ at

888 room temperature with end-over-end mixing. 


\section{Quantification of ssDNA, IgG, or origami on beads}

891 To estimate the amount of SsDNA bound to each bead, we compared the fluorescence

892 of Atto647-labeled DNA on the bead surface to calibrated fluorescent beads (Quantum

893 AlexaFluor 647, Bangs Lab) using confocal microscopy (Figure S1). To determine

894 saturating conditions of IgG and origami pegboards, we titrated the amount of IgG or

895 origami in the coupling reaction and used confocal microscopy to determine the

896 concentration at which maximum coupling was achieved. A comparable amount of

897 origami pegboard coupling was also confirmed with confocal microscopy for beads used

898 in the same experiment.

\section{Quantification of engulfment}

901 30,000 RAW264.7 macrophages were plated in one well of a 96-well glass bottom

902 MatriPlate (Brooks, Catalog \# MGB096-1-2-LG-L) between 12 and $24 \mathrm{hr}$ prior to the 903 experiment. Immediately before adding beads, $100 \mu \mathrm{L}$ of a $1 \mu \mathrm{M}$ solution of 904 benzylguanine-conjugated receptor DNA in engulfment imaging media was added, 905 incubated for $10 \mathrm{~min}$ at room temperature, and washed out 4 times with engulfment 906 imaging media containing $20 \mathrm{mM} \mathrm{MgCl}_{2}$, making sure to leave $\sim 100 \mu \mathrm{L}$ of media 907 covering the cells between washes, and finally leaving the cells in $\sim 300 \mu \mathrm{L}$ of media. $\sim 8$ $908 \times 10^{5}$ beads were added to the well and engulfment was allowed to proceed for $45 \mathrm{~min}$ 909 in the cell incubator. Cells were fixed with 4\% PFA for 10 min and washed into PBS. For

910 figures 4c and 6d, $10 \mathrm{nM}$ AlexaFluor647 anti-biotin IgG (Jackson Immuno Labs, Catalog 911 \# 200-602-211) diluted into PBS containing 3\% BSA was added to each well for 10 912 minutes to label non-internalized beads. Wells were subsequently washed 3 times with

913 PBS. Images were acquired using the High Content Screening (HCS) Site Generator 914 plugin in $\mu$ Manager and at least 100 cells were scored for each condition. When 915 quantifying bead engulfment, cells were selected for analysis based on a threshold of 916 GFP fluorescence, which was held constant throughout analysis for each individual 917 experiment. For figures 3, 4, 6, and S5 the analyzer was blinded during engulfment 918 scoring using the position randomizer plug-in in $\mu$ Manager. For the THP1 cells, $919 \sim 100,000$ cells per condition were spun down, washed into engulfment imaging media, 
920 and coupled to benzylguanine-labeled receptor DNA as described under TIRF imaging.

921 Cells were resuspended into $300 \mu \mathrm{L}$ engulfment imaging media containing $20 \mathrm{mM}$

$922 \mathrm{MgCl}_{2}$ in an Eppendorf tube, $\sim 8 \times 10^{5}$ beads were added to the tube, and the tube was

923 inverted 8x before plating the solution into a round-bottomed 96 well plate (Corning,

924 Catalog \# 38018). Engulfment was allowed to proceed for $45 \mathrm{~min}$ in the cell incubator

925 before the plate was briefly spun and the cells were fixed in 4\% PFA for 10 min. Cells

926 were subsequently washed 3x with PBS by briefly centrifuging the plate and removing

927 the media, and finally moved into a 96-well glass bottom MatriPlate for imaging.

\section{Quantification of engulfment kinetics}

930 RAW264.7 macrophages were plated and prepared in wells of a 96-well glass bottom

931 MatriPlate as described in 'Quantification of engulfment'. Using Multi-Dimensional

932 Acquisition in $\mu$ Manager, 4 positions in the well were marked for imaging at $20 \mathrm{sec}$

933 intervals through at least 7 z-planes. $\sim 4 \times 10^{5}$ Atto647N-labeled $4 S$ origami

934 functionalized beads and $\sim 4 \times 10^{5}$ Atto550N-labeled 4T origami functionalized beads

935 were mixed in an Eppendorf tube, added to the well, and immediately imaged. Bead

936 contacts were identified by counting the number of beads that came into contact with

937 the cells throughout the imaging time. Initiation events were identified by active

938 membrane extension events around the bead. Engulfment completion was identified by

939 complete internalization of the bead by the macrophage. The initiation time was

940 quantified as the amount of time between bead contact (the first frame in which the

941 bead contacted the macrophage) and engulfment initiation (the first frame in which

942 membrane extension around the bead was visualized) and was only measured for

943 beads that were completely internalized by the end of the imaging time. The engulfment

944 time was quantified as the amount of time between engulfment initiation and engulfment

945 completion (the first frame in which the bead has been fully internalized by the cell).

947 Quantification of synapse intensity of DNA-CAR $\gamma$ receptor, tSH2 Syk, PIP $_{3}$ 948 reporter, and actin filaments

949 Phagocytic cups were selected for analysis based on clear initiation of membrane 950 extension around the bead visualized by GFP fluorescence from the DNA-CAR $\gamma$ 
951 receptor. The phagocytic cup and the cell cortex (areas indicated in schematic in figure

952 6b) were traced with a line (6 pixels wide for DNA-CAR $\gamma$ receptor and the tSH2 Syk

953 reporter, and 8 pixels wide for the Akt-PH reporter and phalloidin) at the Z-slice with the

954 clearest cross section of the cup.

955

956 Microscopy and analysis

957 Images were acquired on a spinning disc confocal microscope (Nikon Ti-Eclipse 958 inverted microscope with a Yokogawa CSU-X spinning disk unit and an Andor iXon EM-

959 CCD camera) equipped with a $40 \times 0.95$ NA air and a $100 \times 1.49$ NA oil immersion

960 objective. The microscope was controlled using $\mu$ Manager. For TIRF imaging, images

961 were acquired on the same microscope with a motorized TIRF arm using a Hamamatsu

962 Flash 4.0 camera and the 100x 1.49 NA oil immersion objective.

963

964 Statistics

965 Statistical analysis was performed in Prism 8 (GraphPad, Inc). The statistical test used

966 is indicated in each relevant figure legend.

\section{Acknowledgements}

970 We thank N. Stuurman for help with microscopy and developing the 'image randomizer'

971 plug-in for blinding our analysis as well as the 'Spot Intensity in All Channel' plugin for

972 quantification of our TIRF experiments. We also thank K. McKinley, T. Skokan, C.

973 Gladkova, J. Sheu-Gruttadauria for discussions and critical feedback on this 974 manuscript. M.A.M. was supported by the National Institute of General Medical

975 Sciences of the National Institutes of Health under award number F32GM120990.

976 S.M.D. was supported by the Army Research Office (W911NF-14-1-0507) and Office of

977 Naval Research (N00014-17-1-2627). Funding was provided by the Howard Hughes

978 Medical Institute to R.D.V.

979

980 Author Contributions 
982 N.K., R.D.V., and M.A.M. designed research; N.K. performed research; N.K., R.D.,

983 S.M.D. and M.A.M. contributed new resources; N.K. analyzed data; and N.K., R.D.V.,

984 S.M.D., and M.A.M wrote the paper. 
References

Arnold, M., Cavalcanti-Adam, E. A., Glass, R., Blümmel, J., Eck, W., Kantlehner, M., ... Spatz, J. P. (2004). Activation of integrin function by nanopatterned adhesive interfaces. ChemPhysChem, 5(3), 383-388.

https://doi.org/10.1002/cphc.200301014

Bag, N., Wagenknecht-Wiesner, A., Lee, A., Shi, S., \& Holowka, D. A. (2020). Lipidbased, protein-based, and steric interactions synergize to facilitate transmembrane signaling stimulated by antigen-clustering of IgE receptors. Bioarxiv. https://doi.org/2020.12.26.424347

Bakalar, M. H., Joffe, A. M., Schmid, E. M., Son, S., Podolski, M., \& Fletcher, D. A. (2018). Size-Dependent Segregation Controls Macrophage Phagocytosis of Antibody-Opsonized Targets. Cell. https://doi.org/10.1016/j.cell.2018.05.059

1000

1001

1002

1003

1004

1005

1006

1007

1008

1009

1010

1011

1012

1013

1014

1015

1016

1017

1018

1019

1020

1021

1022

1023

1024

1025

1026

1027

1028

1029

Beekman, J. M., van der Linden, J. A., van de Winkel, J. G. J., \& Leusen, J. H. W. (2008). FcyRI (CD64) resides constitutively in lipid rafts. Immunology Letters, 116(2), 149-155. https://doi.org/10.1016/j.imlet.2007.12.003

Ben M'Barek, K., Molino, D., Quignard, S., Plamont, M. A., Chen, Y., Chavrier, P., \& Fattaccioli, J. (2015). Phagocytosis of immunoglobulin-coated emulsion droplets. Biomaterials, 51, 270-277. https://doi.org/10.1016/j.biomaterials.2015.02.030 Berger, R. M. L., Weck, J. M., Kempe, S. M., Liedl, T., Rädler, J. O., Monzel, C., \& Heuer-Jungemann, A. (2020). Nanoscale Organization of FasL on DNA Origami as a Versatile Platform to Tune Apoptosis Signaling in Cells. BioRxiv, 2020.07.05.187203. https://doi.org/10.1101/2020.07.05.187203

Burroughs, N. J., Köhler, K., Miloserdov, V., Dustin, M. L., van der Merwe, P. A., \& Davis, D. M. (2011). Boltzmann energy-based image analysis demonstrates that extracellular domain size differences explain protein segregation at immune synapses. PLoS Computational Biology, 7(8). https://doi.org/10.1371/journal.pcbi.1002076

Cai, H., Muller, J., Depoil, D., Mayya, V., Sheetz, M. P., Dustin, M. L., \& Wind, S. J. (2018). Full control of ligand positioning reveals spatial thresholds for $\mathrm{T}$ cell receptor triggering. Nature Nanotechnology, 13(7), 610-617. https://doi.org/10.1038/s41565-018-0113-3

Carbone, C. B., Kern, N., Fernandes, R. A., Hui, E., Su, X., Garcia, K. C., \& Vale, R. D. (2017). In vitro reconstitution of T cell receptor-mediated segregation of the CD45 phosphatase. Proceedings of the National Academy of Sciences of the United States of America, 114(44), E9338-E9345.

https://doi.org/10.1073/pnas.1710358114

Chao, M. P., Alizadeh, A. A., Tang, C., Myklebust, J. H., Varghese, B., Gill, S., ... Majeti, R. (2010). Anti-CD47 Antibody Synergizes with Rituximab to Promote Phagocytosis and Eradicate Non-Hodgkin Lymphoma. Cell, 142(5), 699-713. https://doi.org/10.1016/j.cell.2010.07.044

Chew, H. Y., De Lima, P. O., Gonzalez Cruz, J. L., Banushi, B., Echejoh, G., Hu, L., ... Simpson, F. (2020). Endocytosis Inhibition in Humans to Improve Responses to ADCC-Mediating Antibodies. Cell, 180(5), 895-914.e27.

https://doi.org/10.1016/j.cell.2020.02.019 
1053

1054

1055

1056

1057

1058

1059

1060

1061

1062

1063

1064

1065

1066

1067

1068

1069

1070

1071

1072

1073

1074

1075

Chung, M., Koo, B. J., \& Boxer, S. G. (2013). Formation and analysis of topographical domains between lipid membranes tethered by DNA hybrids of different lengths. Faraday Discussions, 161, 333-345; discussion 419-59. https://doi.org/10.1039/c2fd20108a

Davis, S. J., \& van der Merwe, P. A. (2006). The kinetic-segregation model: TCR triggering and beyond. Nature Immunology, 7(8), 803-809. https://doi.org/10.1038/ni1369

Deeg, J., Axmann, M., Matic, J., Liapis, A., Depoil, D., Afrose, J., ... Spatz, J. P. (2013). $T$ Cell Activation is Determined by the Number of Presented Antigens. https://doi.org/10.1021/n1403266t

Delcassian, D., Depoil, D., Rudnicka, D., Liu, M., Davis, D. M., Dustin, M. L., \& Dunlop, I. E. (2013). Nanoscale ligand spacing influences receptor triggering in T cells and NK cells. Nano Letters, 13(11), 5608-5614. https://doi.org/10.1021/nl403252x

Dilillo, D. J., Tan, G. S., Palese, P., \& Ravetch, J. V. (2014). Broadly neutralizing hemagglutinin stalk-specific antibodies require FcR interactions for protection against influenza virus in vivo. Nature Medicine, 20(2), 143-151. https://doi.org/10.1038/nm.3443

Dinic, J., Riehl, A., Adler, J., \& Parmryd, I. (2015). The T cell receptor resides in ordered plasma membrane nanodomains that aggregate upon patching of the receptor. Scientific Reports, 5(May), 1-9. https://doi.org/10.1038/srep10082

Divine, R., Dang, H. V, Ueda, G., Fallas, J. A., Vulovic, I., Sheffler, W., ... Baker, D. (2020). Designed proteins assemble antibodies into modular nanocages. BioRxiv. https://doi.org/10.1101/2020.12.01.406611

Dong, R., Aksel, T., Chan, W., Germain, R. N., Vale, R. D., \& Douglas, S. M. (2021). DNA origami patterning of synthtic $T$ cell receptors rveals spatial control of th sensitivity and kinetics of signal activation. Bioarxiv.

Duchemin, A. M., Ernst, L. K., \& Anderson, C. L. (1994). Clustering of the high affinity Fc receptor for immunoglobulin $\mathrm{G}$ (FcyRl) results in phosphorylation of its associated y-chain. Journal of Biological Chemistry, 269(16), 12111-12117. Eggeling, C., Ringemann, C., Medda, R., Schwarzmann, G., Sandhoff, K., Polyakova, S., ... Hell, S. W. (2009). Direct observation of the nanoscale dynamics of membrane lipids in a living cell. Nature, 457(7233), 1159-1162. https://doi.org/10.1038/nature07596

Erwig, L. P., \& Gow, N. A. R. (2016, February 15). Interactions of fungal pathogens with phagocytes. Nature Reviews Microbiology, Vol. 14, pp. 163-176. https://doi.org/10.1038/nrmicro.2015.21

Fallas, J. A., Ueda, G., Sheffler, W., Nguyen, V., McNamara, D. E., Sankaran, B., ... Baker, D. (2017). Computational design of self-assembling cyclic protein homooligomers. Nature Chemistry, 9(4), 353-360. https://doi.org/10.1038/nchem.2673

Freeman, S. A., Goyette, J., Furuya, W., Anton Van Der Merwe, P., Das, R., Correspondence, S. G., ... Grinstein, S. (2016). Integrins Form an Expanding Diffusional Barrier that Coordinates Phagocytosis. Cell, 164, 128-140. https://doi.org/10.1016/j.cell.2015.11.048

Gonzalez-Quintela, A., Alende, R., Gude, F., Campos, J., Rey, J., Meijide, L. M., ... Vidal, C. (2008). Serum levels of immunoglobulins (IgG, IgA, IgM) in a general adult population and their relationship with alcohol consumption, smoking and common 
metabolic abnormalities. Clinical and Experimental Immunology, 151(1), 42-50. https://doi.org/10.1111/j.1365-2249.2007.03545.x

Goodridge, H. S., Underhill, D. M., \& Touret, N. (2012). Mechanisms of Fc Receptor and Dectin-1 Activation for Phagocytosis. Traffic, 13(8), 1062-1071.

https://doi.org/10.1111/j.1600-0854.2012.01382.x

Griffin, F. M., Griffin, J. A., Leider, J. E., \& Silverstein, S. C. (1975). Studies on the mechanism of phagocytosis. I. Requirements for circumferential attachment of particle-bound ligands to specific receptors on the macrophage plasma membrane. Journal of Experimental Medicine, 142(5), 1263-1282. https://doi.org/10.1084/jem.142.5.1263

Holowka, D., \& Baird, B. (1996). Antigen-Mediated IGE Receptor Aggregation and Signaling: A Window on Cell Surface Structure and Dynamics. Annual Review of Biophysics and Biomolecular Structure, 25(1), 79-112. https://doi.org/10.1146/annurev.bb.25.060196.000455

Hong, F., Zhang, F., Liu, Y., \& Yan, H. (2017). DNA Origami: Scaffolds for Creating Higher Order Structures. In Chemical Reviews (Vol. 117). https://doi.org/10.1021/acs.chemrev.6b00825

Huang, M. M., Indik, Z., Brass, L. F., Hoxie, J. A., Schreiber, A. D., \& Brugge, J. S. (1992). Activation of FcyRII induces tyrosine phosphorylation of multiple proteins including FcyRII. Journal of Biological Chemistry, 267(8), 5467-5473.

Huang, X., Williams, J. Z., Chang, R., Li, Z., Burnett, C. E., Hernandez-Lopez, R., ... Desai, T. A. (2020). DNA scaffolds enable efficient and tunable functionalization of biomaterials for immune cell modulation. Nature Nanotechnology. https://doi.org/10.1038/s41565-020-00813-z

Jaumouillé, V., Farkash, Y., Jaqaman, K., Das, R., Lowell, C. A., \& Grinstein, S. (2014). Actin cytoskeleton reorganization by syk regulates fcy receptor responsiveness by increasing its lateral mobility and clustering. Developmental Cell, 29(5), 534-546. https://doi.org/10.1016/j.devcel.2014.04.031

Kabouridis, P. S. (2006, January 9). Lipid rafts in T cell receptor signalling (review). Molecular Membrane Biology, Vol. 23, pp. 49-57. https://doi.org/10.1080/09687860500453673

Kato, Y., Abbott, R. K., Freeman, B. L., Irvine, D. J., Schief, W. R., Crotty, S., ... Menis, S. (2020). Multifaceted Effects of Antigen Valency on B Cell Response Composition and Differentiation In\&nbsp;Vivo. https://doi.org/10.1016/j.immuni.2020.08.001

Katsumata, O., Hara-Yokoyama, M., Sautès-Fridman, C., Nagatsuka, Y., Katada, T., Hirabayashi, Y., ... Furuyama, S. (2001). Association of FcyRII with Low-Density Detergent-Resistant Membranes Is Important for Cross-Linking-Dependent Initiation of the Tyrosine Phosphorylation Pathway and Superoxide Generation. The Journal of Immunology, 167(10), 5814-5823. https://doi.org/10.4049/jimmunol.167.10.5814

Krobath, H., Rózycki, B., Lipowsky, R., \& Weikl, T. R. (2009). Binding cooperativity of membrane adhesion receptors. Soft Matter, 5(17), 3354-3361. https://doi.org/10.1039/b902036e

Krobath, H., Rózycki, B., Lipowsky, R., \& Weikl, T. R. (2011). Line tension and stability of domains in cell-adhesion zones mediated by long and short receptor-ligand complexes. PLoS ONE, 6(8). https://doi.org/10.1371/journal.pone.0023284 
1122

1123

1124

1125

1126

1127

1128

1129

1130

1131

1132

1133

1134

1135

1136

1137

1138

1139

1140

1141

1142

1143

1144

1145

1146

1147

1148

1149

1150

1151

1152

1153

1154

1155

1156

1157

1158

1159

1160

1161

1162

1163

1164

1165

1166

1167

Kwiatkowska, K., \& Sobota, A. (2001). The clustered Fcy receptor II is recruited to Lyncontaining membrane domains and undergoes phosphorylation in a cholesteroldependent manner. European Journal of Immunology, 31(4), 989-998. https://doi.org/10.1002/1521-4141(200104)31:4<989::AID-IMMU989>3.0.CO;2-V

Li, P., Jiang, N., Nagarajan, S., Wohlhueter, R., Selvaraj, P., \& Zhu, C. (2007). Affinity and kinetic analysis of Fcy receptor IIIa (CD16a) binding to IgG ligands. Journal of Biological Chemistry, 282(9), 6210-6221. https://doi.org/10.1074/jbc.M609064200

Lin, J., Kurilova, S., Scott, B. L., Bosworth, E., Iverson, B. E., Bailey, E. M., \& Hoppe, A. D. (2016). TIRF imaging of Fc gamma receptor microclusters dynamics and signaling on macrophages during frustrated phagocytosis. BMC Immunology, 17, 5. https://doi.org/10.1186/s12865-016-0143-2

Lopes, F. B., Bálint, Š., Valvo, S., Felce, J. H., Hessel, E. M., Dustin, M. L., \& Davis, D. M. (2017). Membrane nanoclusters of FcyRI segregate from inhibitory SIRPa upon activation of human macrophages. The Journal of Cell Biology, jcb.201608094. https://doi.org/10.1083/jcb.201608094

Lu, J., Ellsworth, J. L., Hamacher, N., Oak, S. W., \& Sun, P. D. (2011). Crystal structure of Fcy receptor I and its implication in high affinity $\mathrm{Y}$-immunoglobulin binding. Journal of Biological Chemistry, 286(47), 40608-40613. https://doi.org/10.1074/jbc.M111.257550

Ma, Y., Lim, Y., Benda, A., Goyette, J., \& Gaus, K. (2020). Clustering of CD3ろ is sufficient to initiate $T$ cell receptor signaling. https://doi.org/10.1101/2020.02.17.953463

McCall, M. N., Shotton, D. M., \& Barclay, A. N. (1992). Expression of soluble isoforms of rat CD45. Analysis by electron microscopy and use in epitope mapping of antiCD45R monoclonal antibodies. Immunology, 76(2), 310-317. Retrieved from http://www.ncbi.nlm.nih.gov/pubmed/1378817

Morrissey, M. A., Kern, N., \& Vale, R. D. (2020). CD47 Ligation Repositions the Inhibitory Receptor SIRPA to Suppress Integrin Activation and Phagocytosis. Immunity, 53(2), 290-302.e6. https://doi.org/10.1016/j.immuni.2020.07.008

Morrissey, M. A., Williamson, A. P., Steinbach, A. M., Roberts, E. W., Kern, N., Headley, M. B., \& Vale, R. D. (2018). Chimeric antigen receptors that trigger phagocytosis. ELife. https://doi.org/10.7554/eLife.36688

Nimmerjahn, F., \& Ravetch, J. V. (2005). Translating basic mechanisms of IgG effector activity into next generation cancer therapies. IECON Proceedings (Industrial Electronics Conference), 2005(May), 1104-1109. https://doi.org/10.1109/IECON.2005.1569059

Nimmerjahn, F., \& Ravetch, J. V. (2008). Fcy receptors as regulators of immune responses. Nature Reviews Immunology. https://doi.org/10.1038/nri2206

Rosano, C., Arosio, P., \& Bolognesi, M. (1999). The X-ray three-dimensional structure of avidin. Biomolecular Engineering, 16(1-4), 5-12. https://doi.org/10.1016/S10503862(99)00047-9

Rothemund, P. W. K. (2006). Folding DNA to create nanoscale shapes and patterns. Nature, 440(7082), 297-302. https://doi.org/10.1038/nature04586

Rózycki, B., Lipowsky, R., \& Weikl, T. R. (2010). Segregation of receptor-ligand complexes in cell adhesion zones: Phase diagrams and the role of thermal membrane roughness. New Journal of Physics, 12. https://doi.org/10.1088/1367- 


\section{0/12/9/095003}

Schmid, E. M., Bakalar, M. H., Choudhuri, K., Weichsel, J., Ann, H. S., Geissler, P. L., ... Fletcher, D. A. (2016). Size-dependent protein segregation at membrane interfaces. Nature Physics, 12(7), 704-711. https://doi.org/10.1038/nphys3678 Seeman, N. C. (2010). Nanomaterials Based on DNA. Annual Review of Biochemistry, 79(1), 65-87. https://doi.org/10.1146/annurev-biochem-060308-102244

Seifert, O., Plappert, A., Fellermeier, S., Siegemund, M., Pfizenmaier, K., \& Kontermann, R. E. (2014). Tetravalent Antibody-scTRAIL Fusion Proteins with Improved Properties. Molecular Cancer Therapeutics, 13(1), 101-111. https://doi.org/10.1158/1535-7163.MCT-13-0396

Shaw, A., Hoffecker, I. T., Smyrlaki, I., Rosa, J., Grevys, A., Bratlie, D., ... Högberg, B. (2019). Binding to nanopatterned antigens is dominated by the spatial tolerance of antibodies. Nature Nanotechnology, 14(2), 184-190. https://doi.org/10.1038/s41565-018-0336-3

Sil, D., Lee, J. B., Luo, D., Holowka, D., \& Baird, B. (2007). Trivalent Ligands with Rigid DNA Spacers Reveal Structural Requirements For IgE Receptor Signaling in RBL Mast Cells. ACS Chemical Biology, 2(10), 674-684. https://doi.org/10.1021/cb7001472

Simons, K., \& Ikonen, E. (1997). Functional rafts in cell membranes. Nature, 387(6633), 569-572.

Sobota, A., Strzelecka-Kiliszek, A., Gładkowska, E., Yoshida, K., Mrozińska, K., \& Kwiatkowska, K. (2005). Binding of IgG-Opsonized Particles to FcyR Is an Active Stage of Phagocytosis That Involves Receptor Clustering and Phosphorylation. The Journal of Immunology, 175(7), 4450-4457. https://doi.org/10.4049/jimmunol.175.7.4450

Sohn, H. W., Tolar, P., Jin, T., \& Pierce, S. K. (2006). Fluorescence resonance energy transfer in living cells reveals dynamic membrane changes in the initiation of B cell signaling. Proceedings of the National Academy of Sciences of the United States of America, 103(21), 8143-8148. https://doi.org/10.1073/pnas.0509858103

Stone, M. B., Shelby, S. A., Nńñez, M. F., Wisser, K., \& Veatch, S. L. (2017). Protein sorting by lipid phase-like domains supports emergent signaling function in $b$ lymphocyte plasma membranes. ELife, 6, 1-33. https://doi.org/10.7554/eLife.19891

Stuurman, N., Edelstein, A., Amodaj, N., Hoover, K., \& Vale, R. (2010, October). Computer control of microscopes using manager. Current Protocols in Molecular Biology, p. Unit14.20. https://doi.org/10.1002/0471142727.mb1420s92

Swanson, J. A., \& Baer, S. C. (1995). Phagocytosis by zippers and triggers. Trends in Cell Biology, 5(3), 89-93. https://doi.org/10.1016/S0962-8924(00)88956-4

Taylor, M. J., Husain, K., Gartner, Z. J., Mayor, S., \& Vale, R. D. (2017). A DNA-Based T Cell Receptor Reveals a Role for Receptor Clustering in Ligand Discrimination. Cell, 169(1), 108-119.e20. https://doi.org/10.1016/j.cell.2017.03.006

Uchida, J., Hamaguchi, Y., Oliver, J. A., Ravetch, J. V., Poe, J. C., Haas, K. M., \& Tedder, T. F. (2004). The innate mononuclear phagocyte network depletes B lymphocytes through Fc receptor-dependent mechanisms during anti-CD20 antibody immunotherapy. Journal of Experimental Medicine, 199(12), 1659-1669. https://doi.org/10.1084/jem.20040119

Ueda, G., Antanasijevic, A., Fallas, J. A., Sheffler, W., Copps, J., Ellis, D., ... Baker, D. 

(2020). Tailored design of protein nanoparticle scaffolds for multivalent presentation of viral glycoprotein antigens. ELife, 9, 1-30. https://doi.org/10.7554/ELIFE.57659 Veneziano, R., Moyer, T. J., Stone, M. B., Shepherd, T. R., Schief, W. R., Irvine, D. J., \& Bathe, M. (2020). Role of nanoscale antigen organization on B-cell activation probed using DNA origami. BioRxiv, 2020.02.16.951475. https://doi.org/10.1101/2020.02.16.951475

Watanabe, M., Wallace, P. K., Keler, T., Deo, Y. M., Akewanlop, C., \& Hayes, D. F. (1999). Antibody dependent cellular phagocytosis (ADCP) and antibody dependent cellular cytotoxicity (ADCC) of breast cancer cells mediated by bispecific antibody, MDX-210. Breast Cancer Research and Treatment, 53(3), 199-207. https://doi.org/10.1023/A:1006145507567

Weiskopf, K., Ring, A. M., Ho, C. C. M., Volkmer, J. P., Levin, A. M., Volkmer, A. K., ... Garcia, K. C. (2013). Engineered SIRPa variants as immunotherapeutic adjuvants to anticancer antibodies. Science, 341(6141), 88-91. https://doi.org/10.1126/science.1238856

Weiskopf, K., \& Weissman, I. L. (2015). Macrophages are critical effectors of antibody therapies for cancer. MAbs, Vol. 7, pp. 303-310. https://doi.org/10.1080/19420862.2015.1011450

Woollett, G. R., Williams, A. F., \& Shotton, D. M. (1985). Visualisation by low-angle shadowing of the leucocyte-common antigen. A major cell surface glycoprotein of lymphocytes. The EMBO Journal, 4(11), 2827-2830. https://doi.org/10.1002/j.14602075.1985.tb04010.x

Zhang, X., Olsen, H. S., Chen, S., So, E., Zhou, H., Burch, E., ... Strome, S. E. (2016). Anti-CD20 Antibody with Multimerized Fc Domains: A Novel Strategy To Deplete B Cells and Augment Treatment of Autoimmune Disease. The Journal of Immunology, 196(3), 1165-1176. https://doi.org/10.4049/jimmunol.1501755

Zhang, Y., Hoppe, A. D., \& Swanson, J. A. (2010). Coordination of Fc receptor signaling regulates cellular commitment to phagocytosis. Proceedings of the National Academy of Sciences of the United States of America, 107(45), 19332-19337. https://doi.org/10.1073/pnas.1008248107

Zhao, K., Deng, H., Chen, H., Ross, K. A., Petříček, V., Günther, G., ... Gegenwart, P. (2020). Structure of CD20 in complex with the therapeutic monoclonal antibody rituximab. Science, 367(6483), 1218-1223. https://doi.org/10.1126/science.aaz9356

Zhu, J. W., Brdicka, T., Katsumoto, T. R., Lin, J., \& Weiss, A. (2008). Structurally Distinct Phosphatases CD45 and CD148 Both Regulate B Cell and Macrophage Immunoreceptor Signaling. Immunity, 28(2), 183-196. https://doi.org/10.1016/j.immuni.2007.11.024 
bioRxiv preprint doi: https://doi.org/10.1101/2021.03.18,436011; this version posted March 18, 2021. The copyright holder for this preprint (which was not certified by peer review) is the author/funder, who has granted bioRxiv a license to display the preprint in perpetuity. It is made available under aCC-BY-NC-ND 4.0 International license.

\section{Figure 1}

A

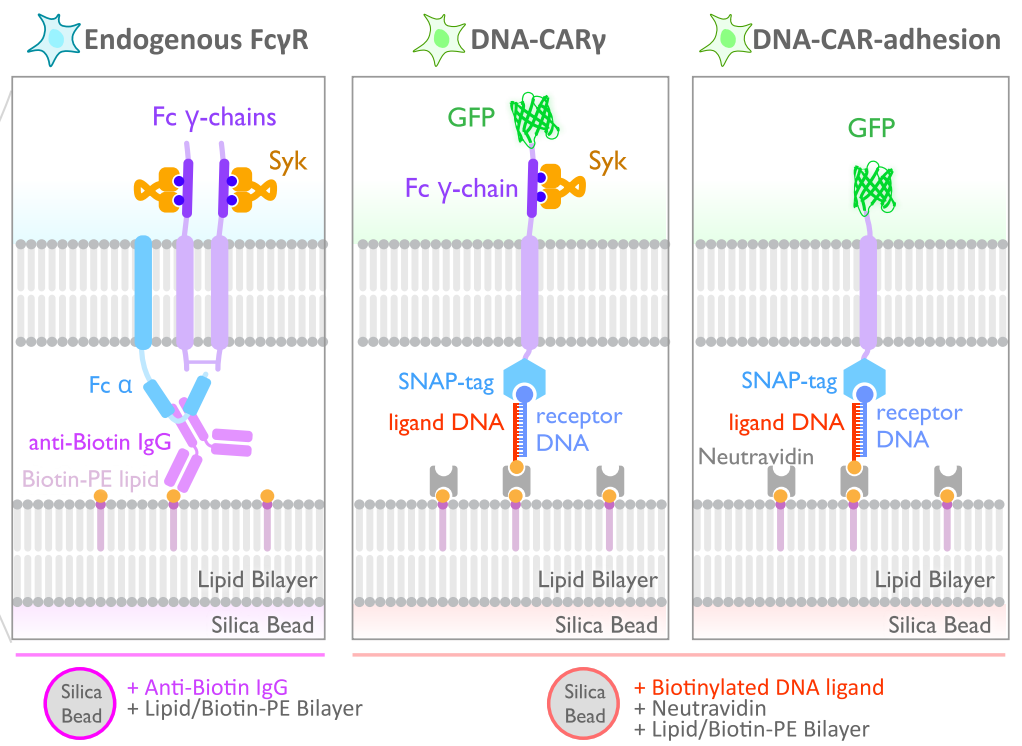

B

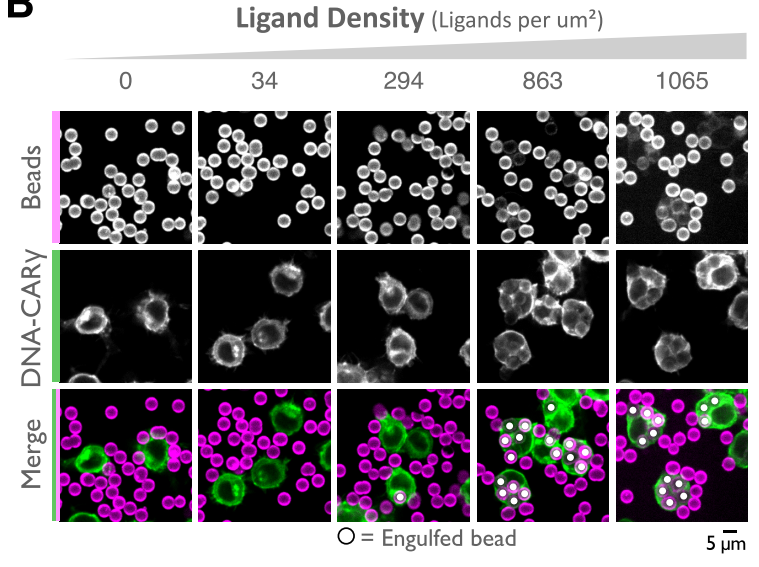

DNA-CARY
C

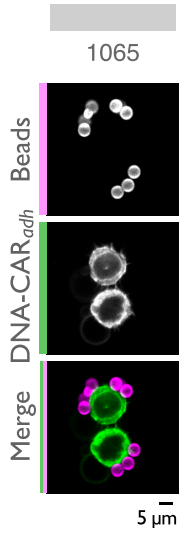

DNA-CAR adhesion
D
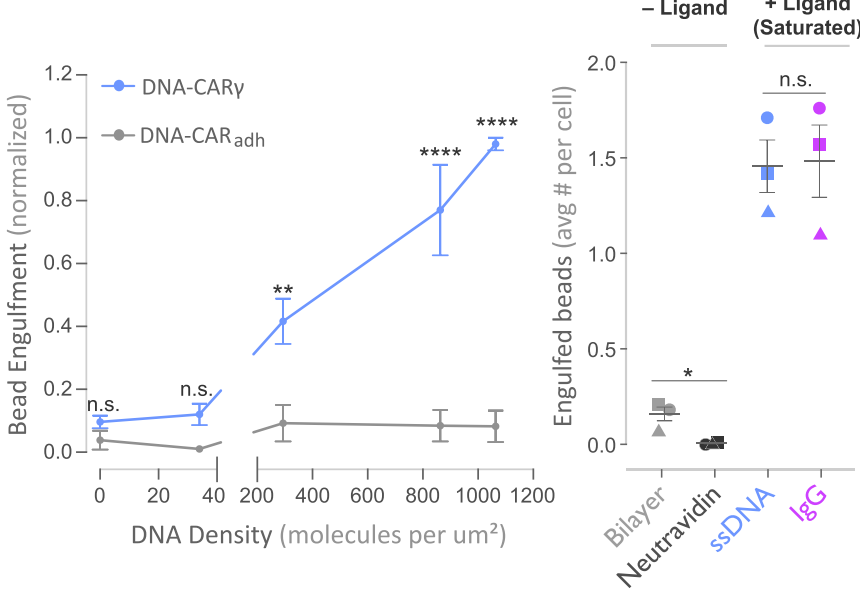
bioRxiv preprint doi: https://doi.org/10.1101/2021.03.18.436011; this version posted March 18,2021 . The copyright holder for this preprint (which was not certified by peer review) is the author/funder, who has granted bioRxiv a license to display the preprint in perpetuity. It is made available under aCC-BY-NC-ND 4.0 International license.

\section{Figure 2}

A

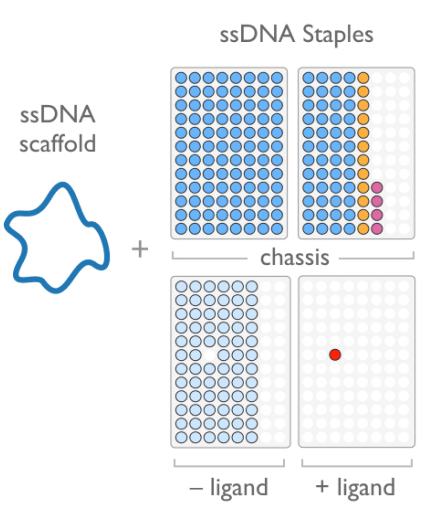

C

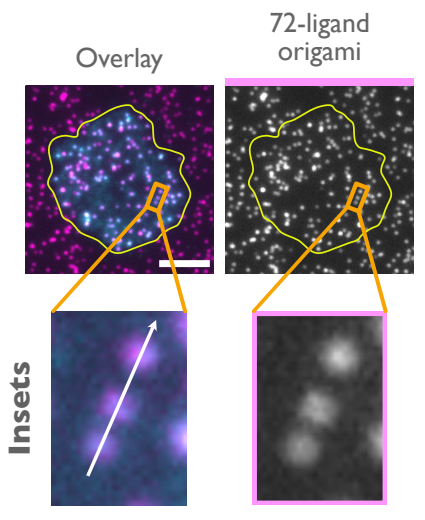

D

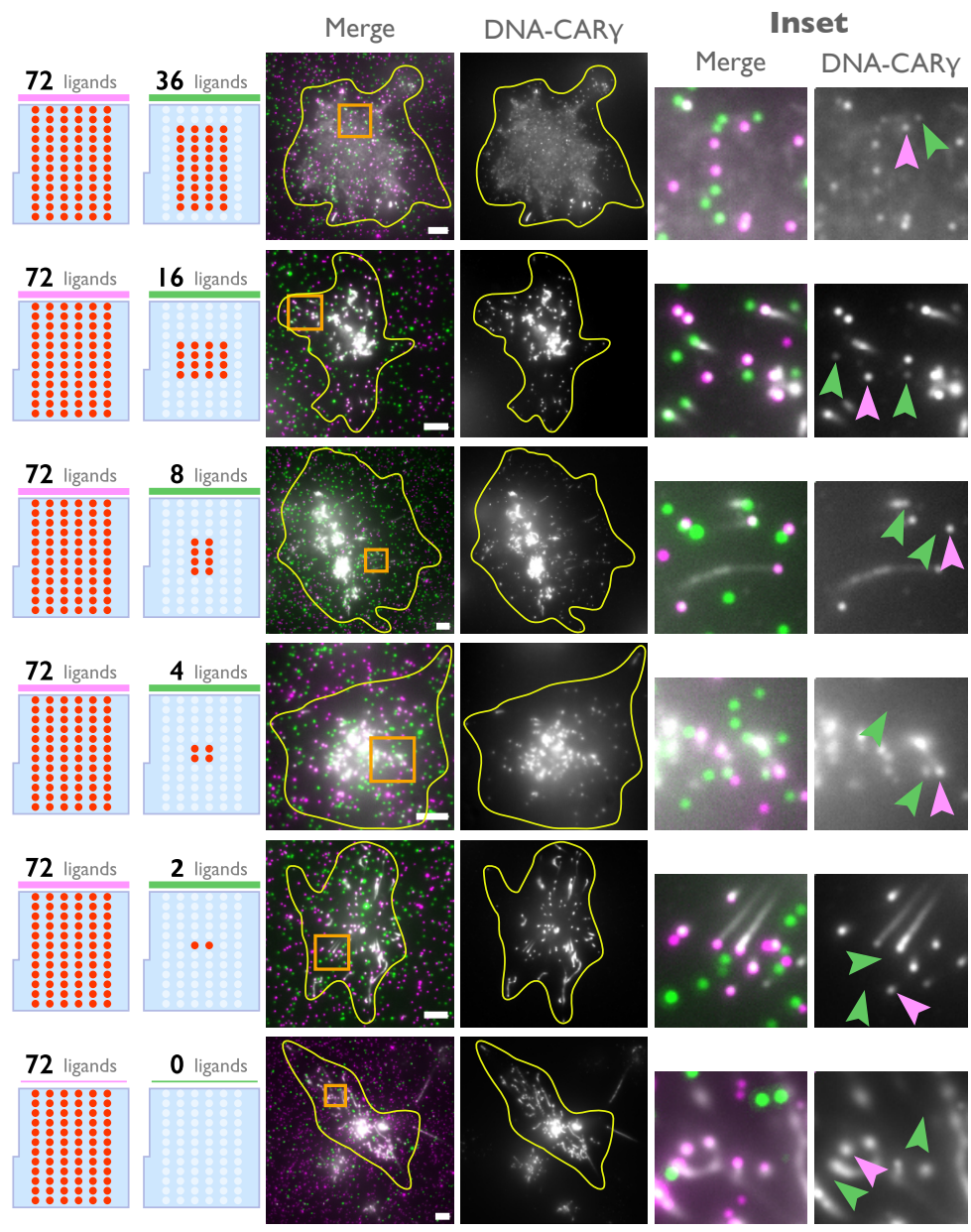

DNA origami pegboard

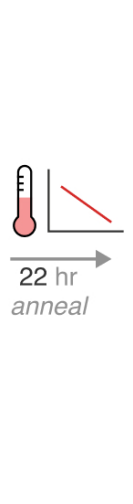

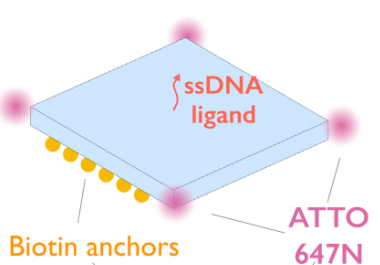

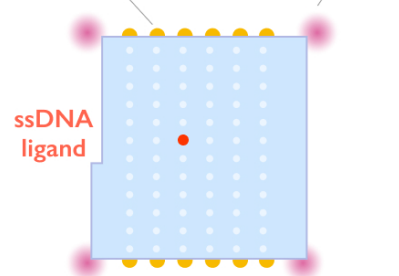

B
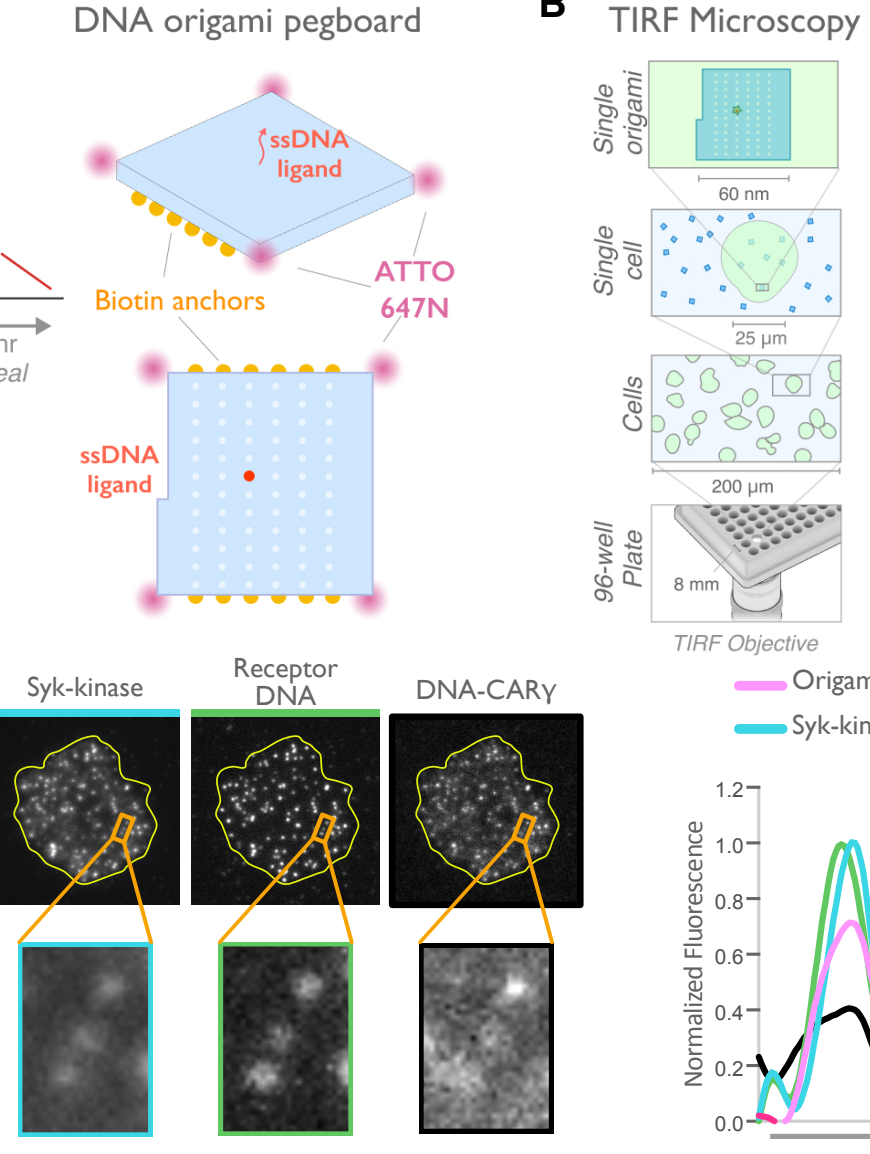

TIRF Objective
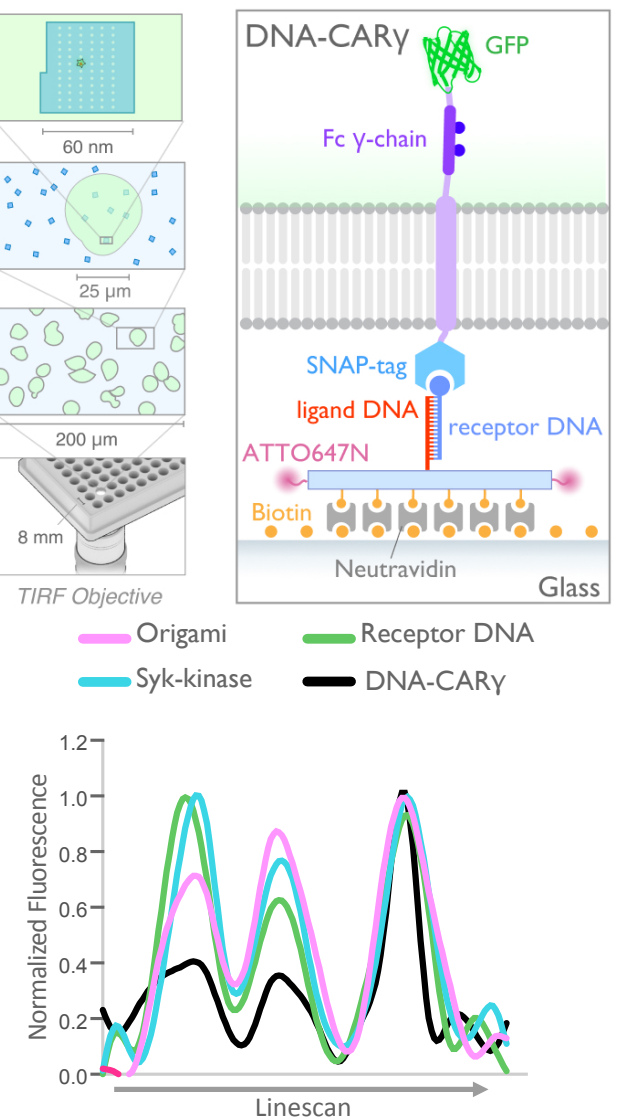

E
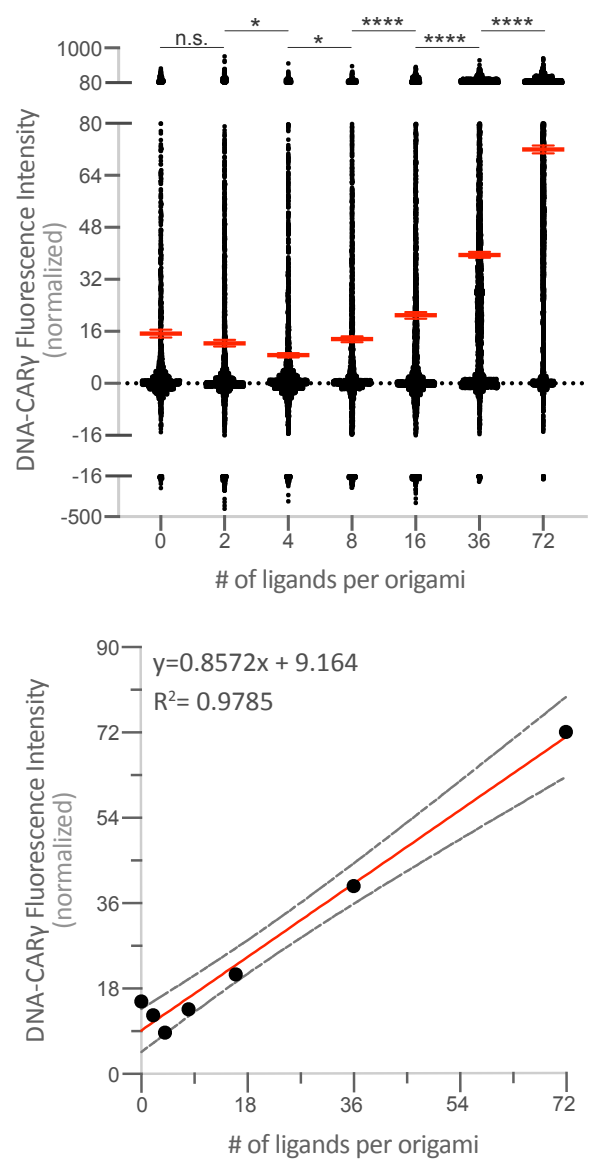
bioRxiv preprint doi: https://doi.org/10.1101/2021.03.18.436011; this version posted March 18, 2021. The copyright holder for this preprint (which was not certified by peer review) is the author/funder, who has granted bioRxiv a license to display the preprint in perpetuity. It is made available under aCC-BY-NC-ND 4.0 International license.

\section{Figure 3}

A

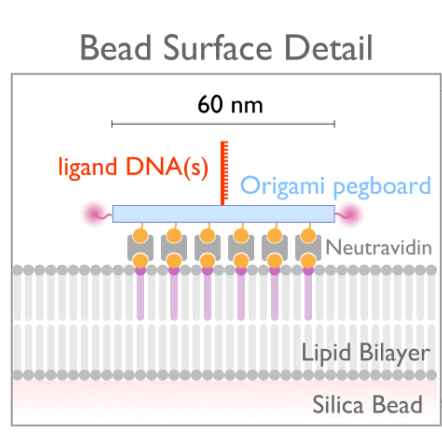

Functionalized Silica Bead
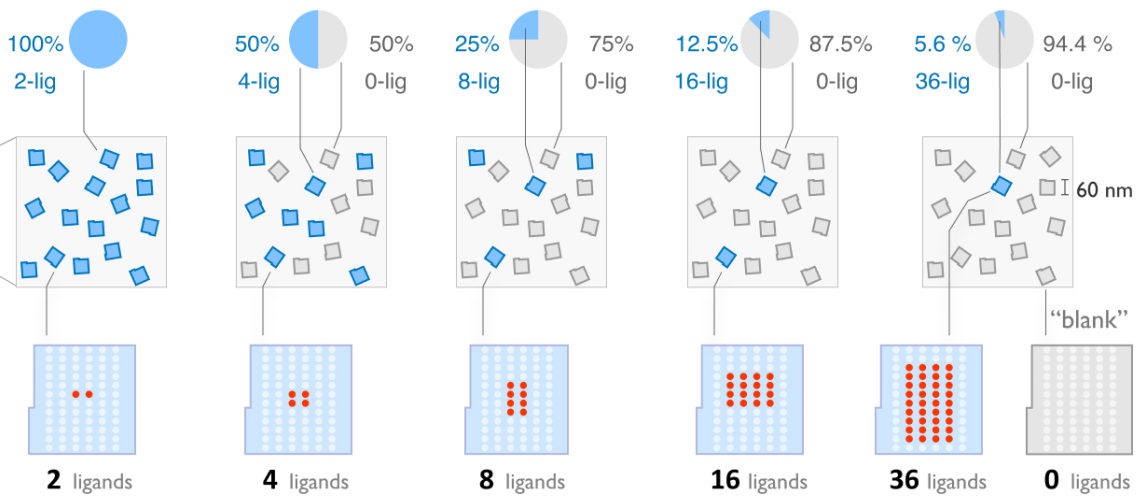

B

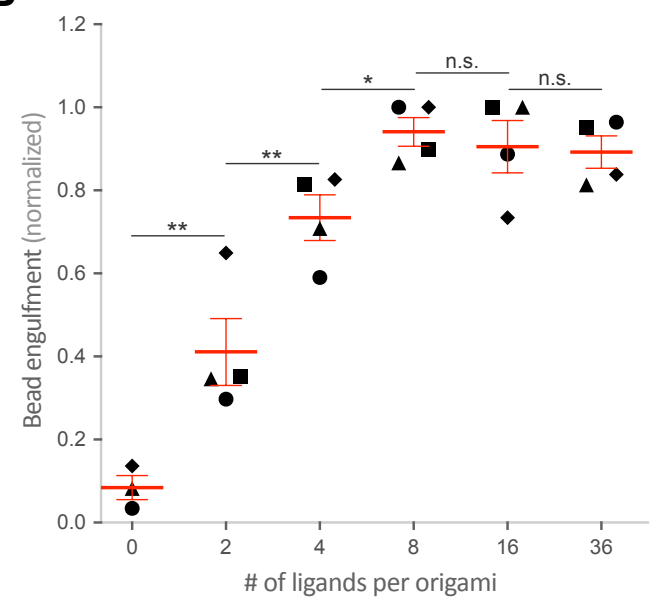

C

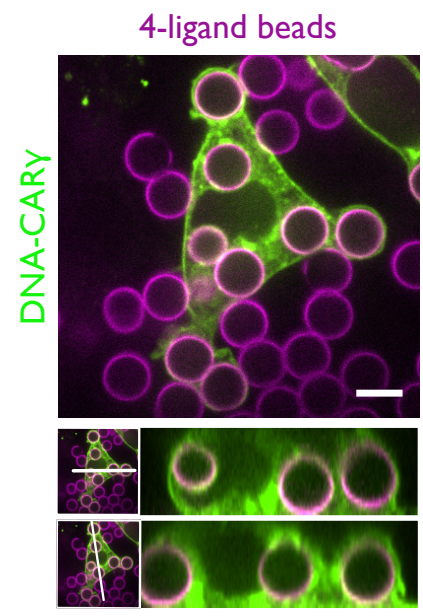

D

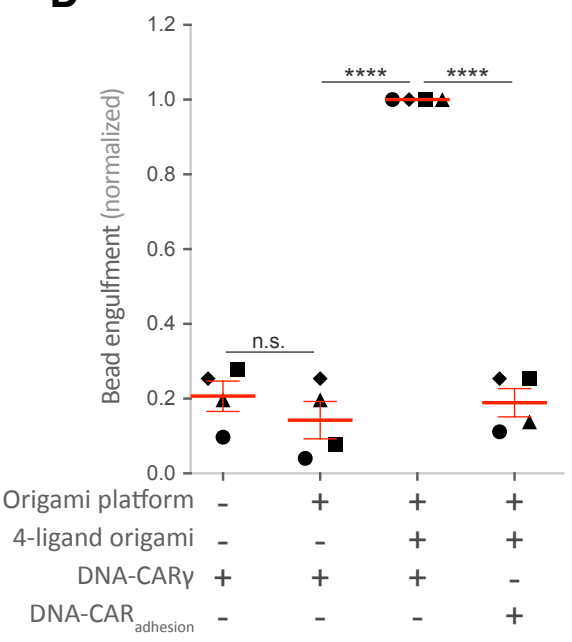


bioRxiv preprint doi: https://doi org/10.1101/2021.03.18.436011; this version posted March 18,2021 . The copyright holder for this preprint (which was not certified by peer review) is the author/funder, who has granted bioRxiv a license to display the preprint in perpetuity. It is made available under aCC-BY-NC-ND 4.0 International license.

\section{Figure 4}

A

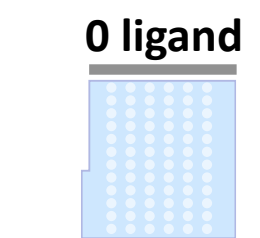

Beads
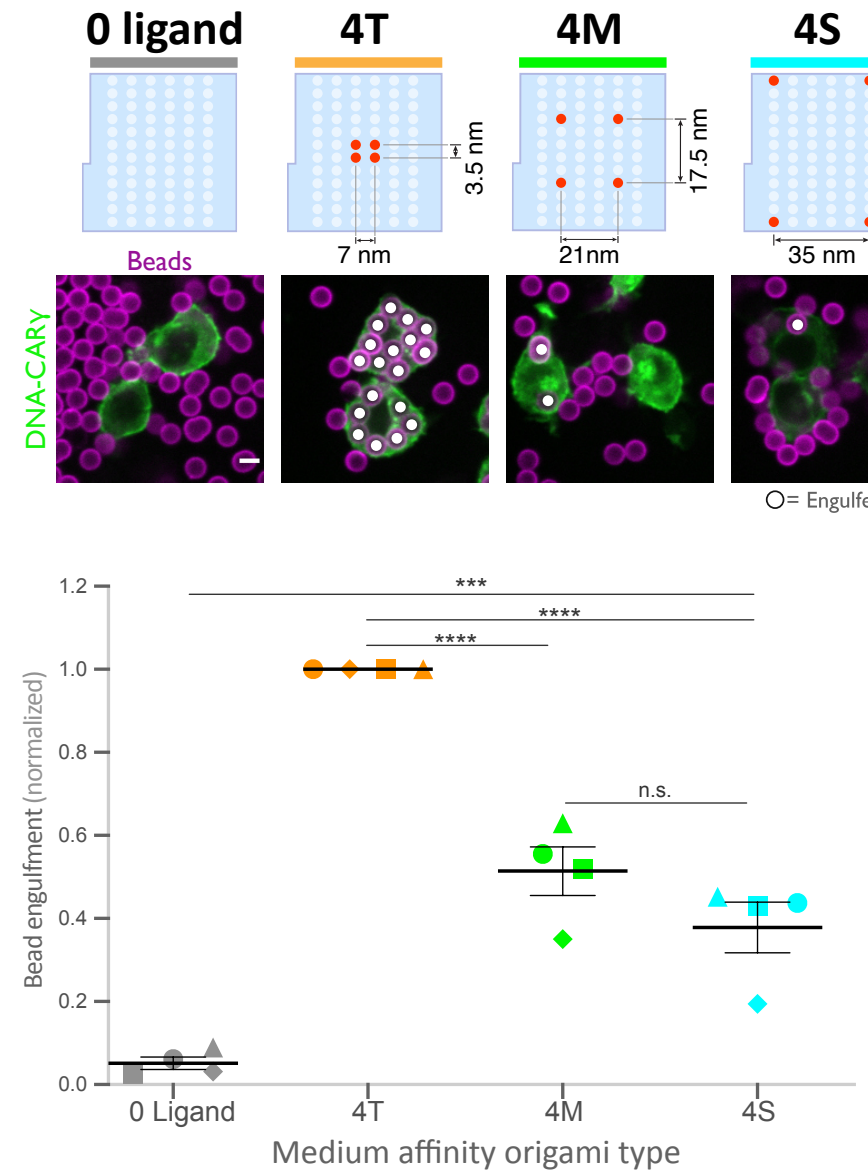

B
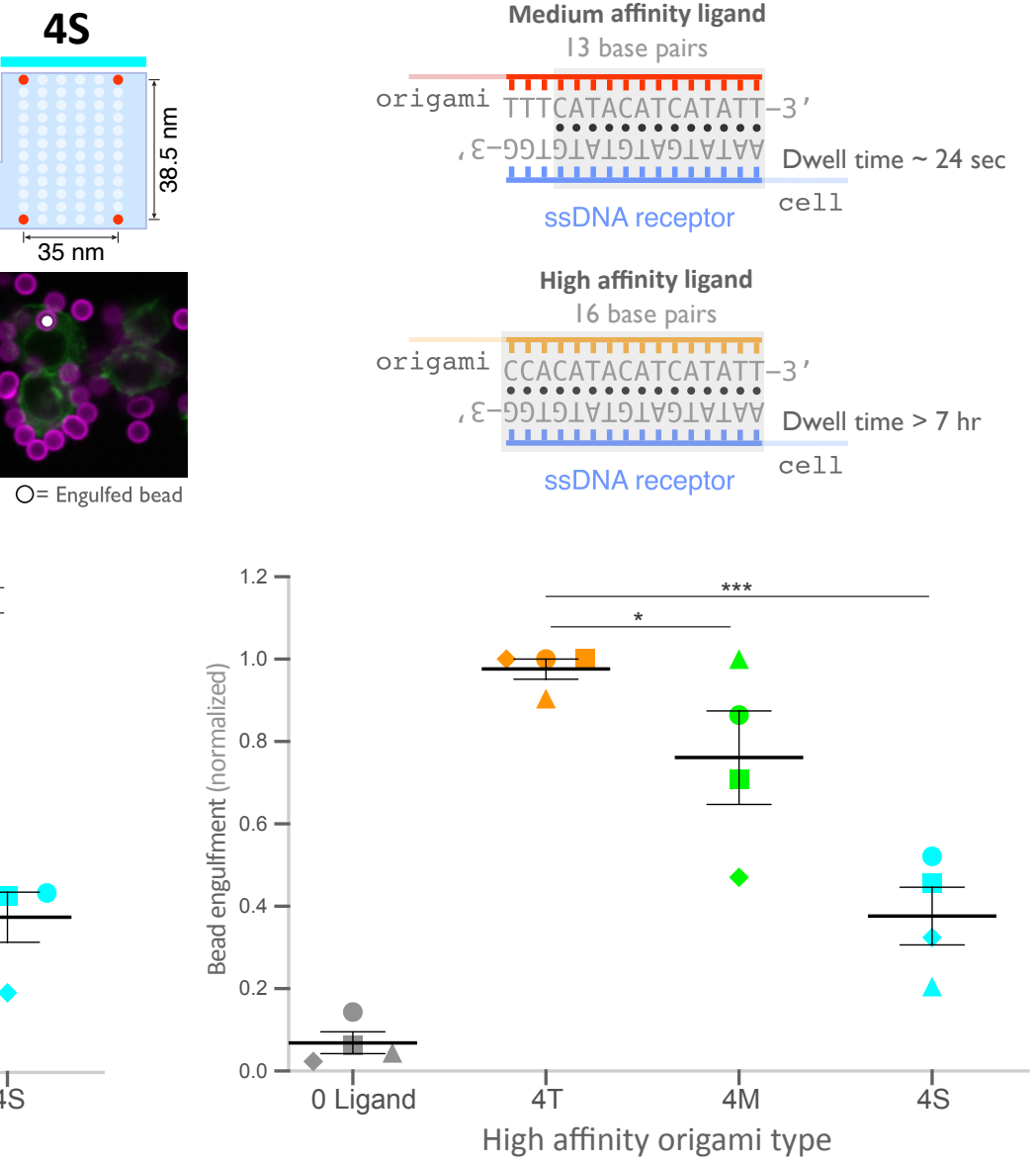


\section{Figure 5}

A

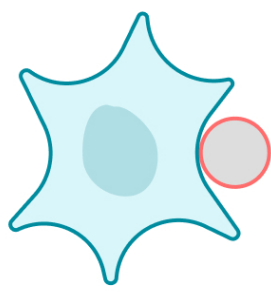

Binding
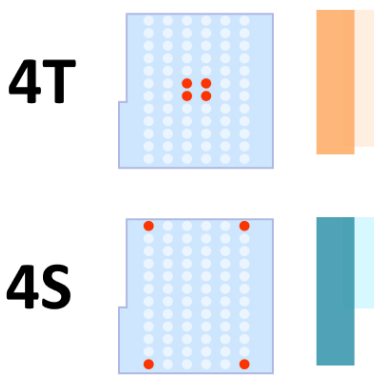

B

Time (min)
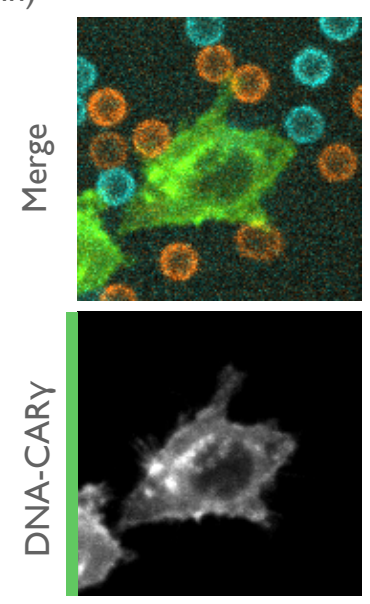

C

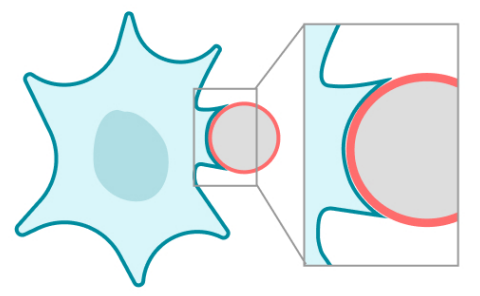

Initiation

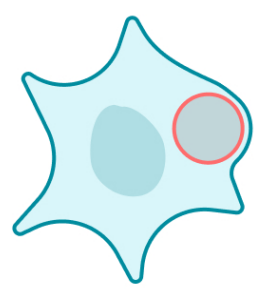

Completion

$69 \pm 9 \%$

$66 \pm 8 \%$

$95 \pm 5 \%$

$* * * *$

$61 \pm 9 \%$

$39 \pm 11 \%$

$24 \pm 8 \%$

Overall

$\%$ success

success
Initiation time

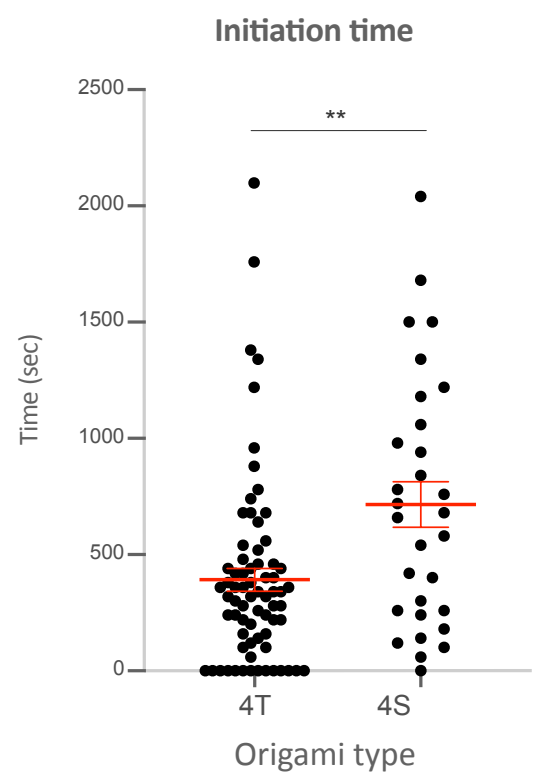

Origami type
6.66
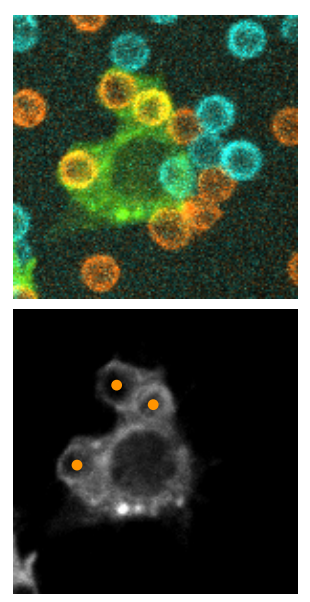

D

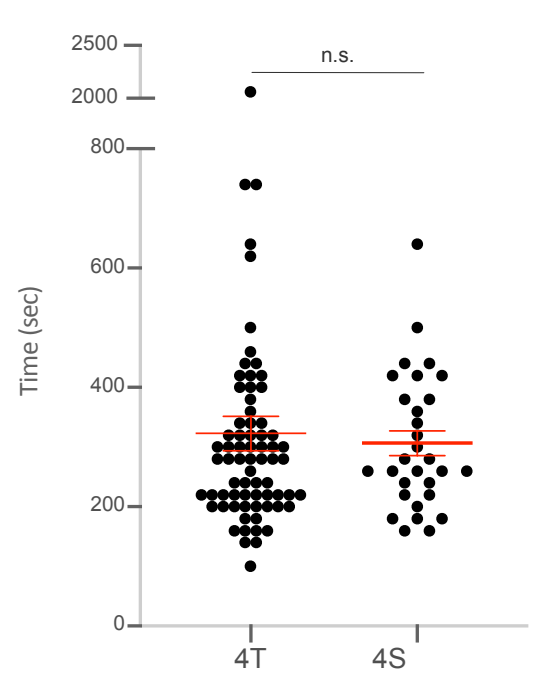

Origami type
13.33
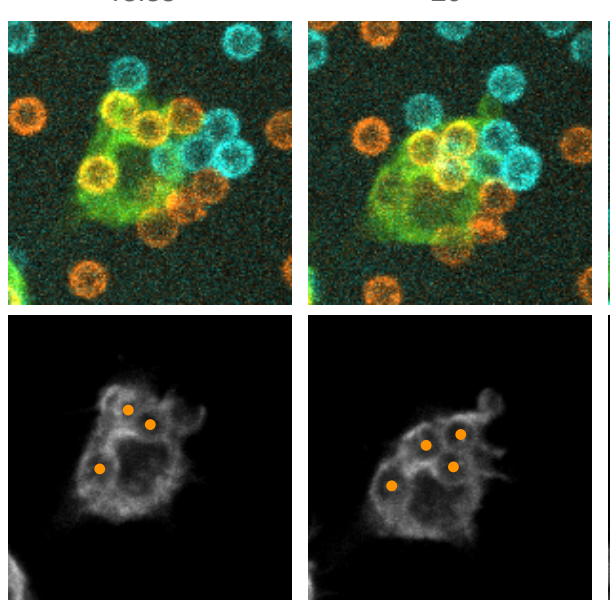

E
= Engulfed bead
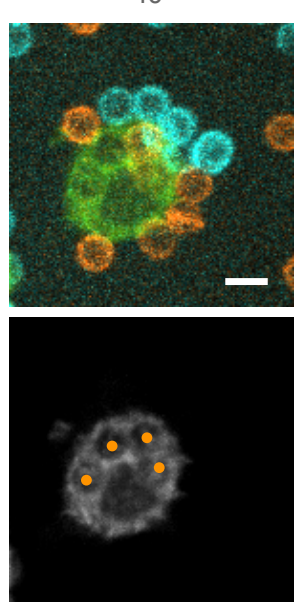

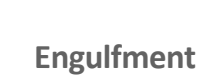

probability

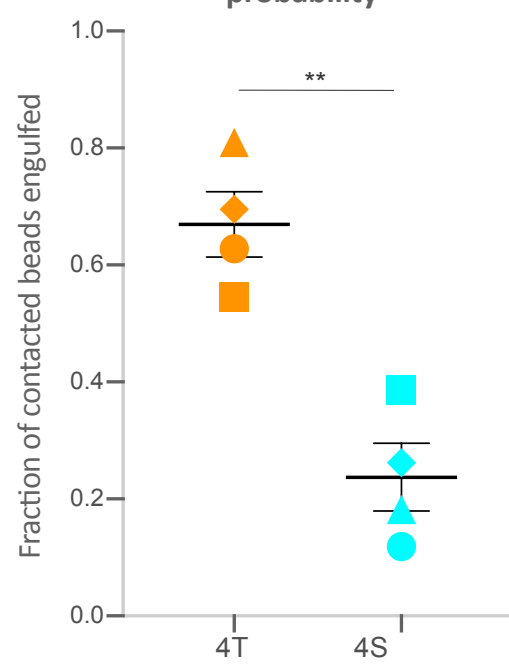

Origami type 
bioRxiv preprint doi: https://doi.org/10.1101/2021 0318.436011 ; this version posted March 18, 2021. The copyright holder for this preprint (which was not certified by peer review) is the author/funder, who has granted bioRxiv a license to display the preprint in perpetuity. It is made available under aCC-BY-NC-ND 4.0 International license.

\section{Figure 6}

A

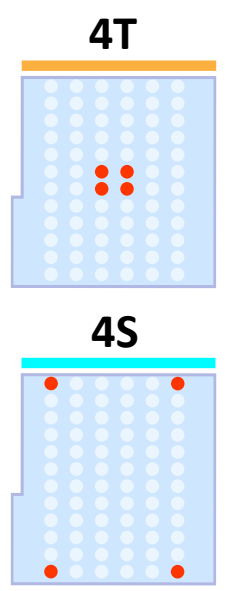

B

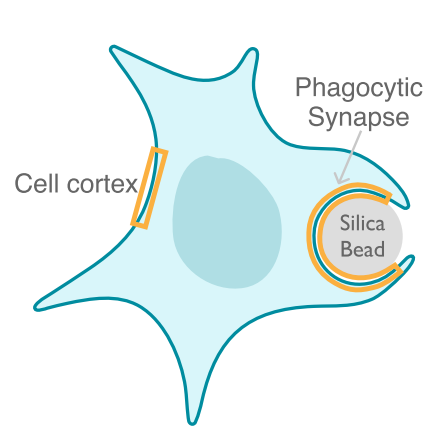

C

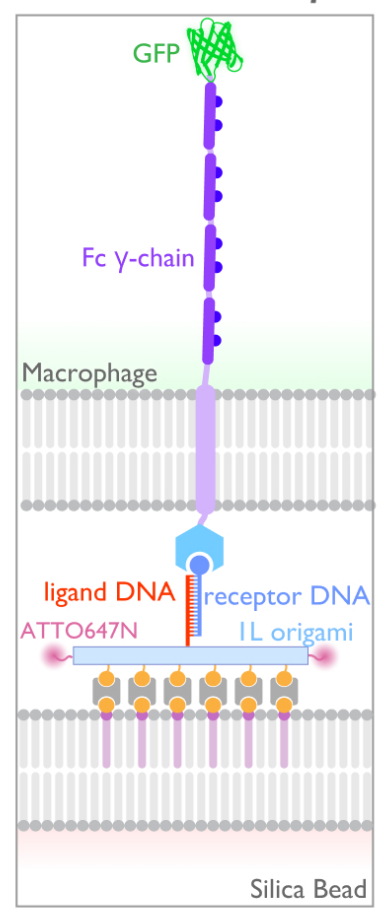

DNA-CARY
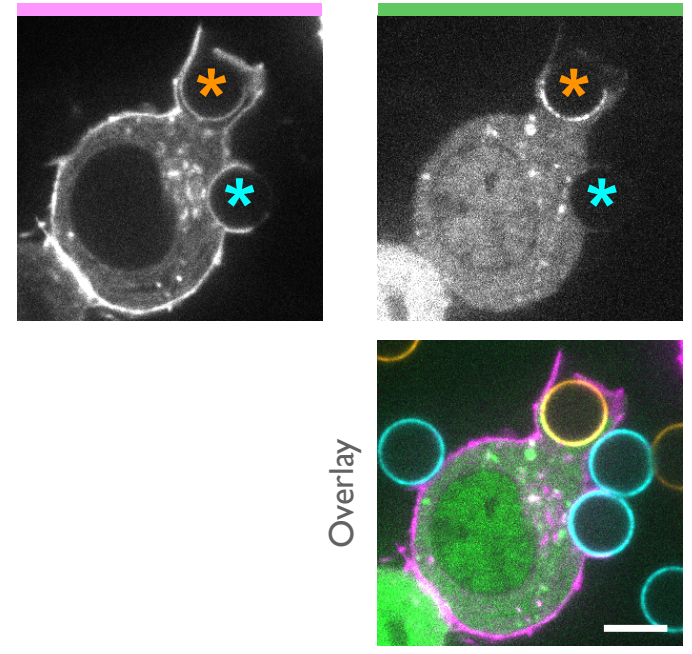

tSH2 Syk
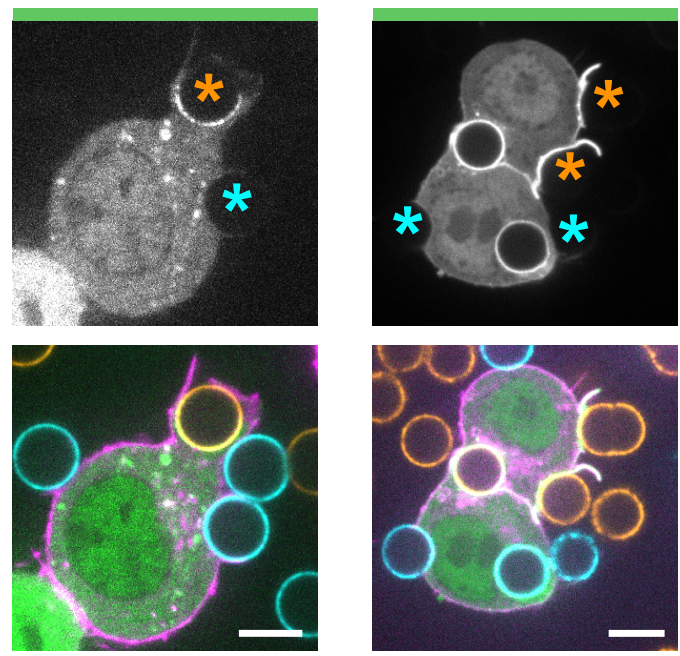

Actin
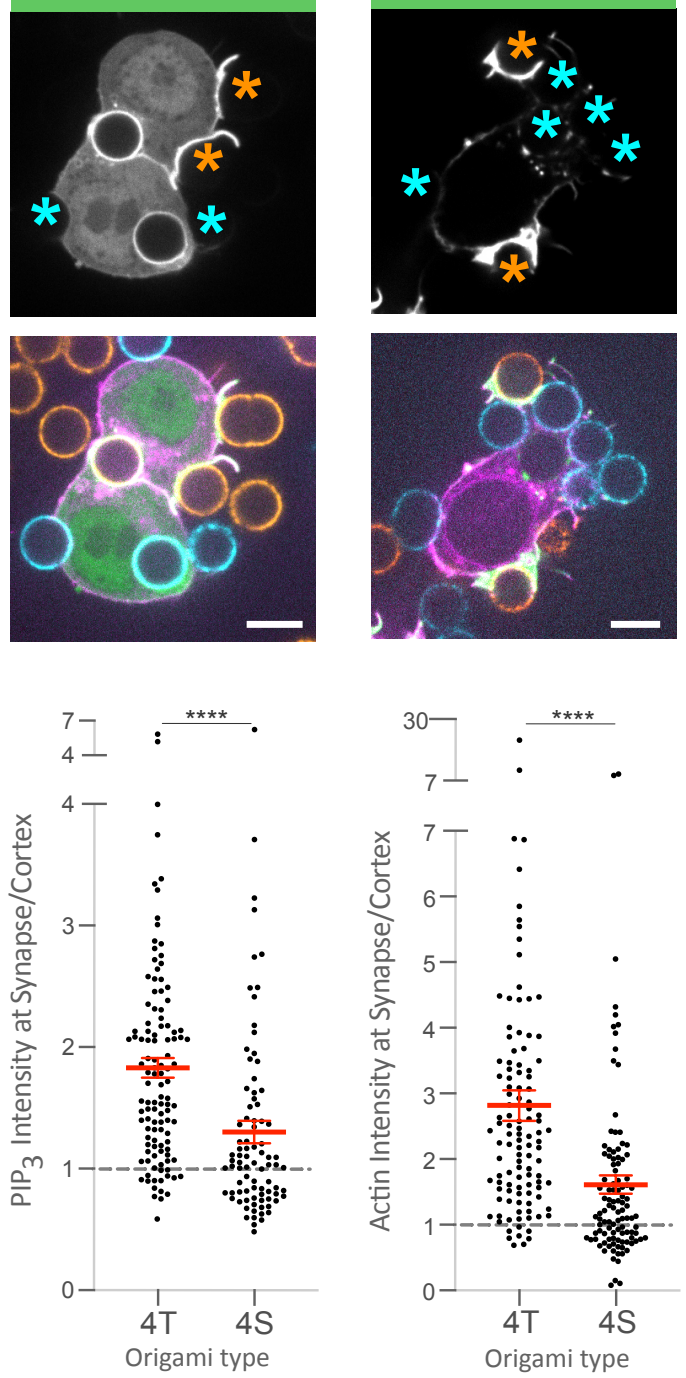

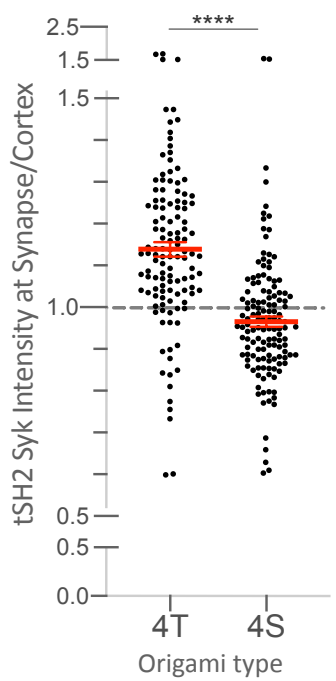

DNA-CAR-I $x y-3 \times \Delta I T A M$

D
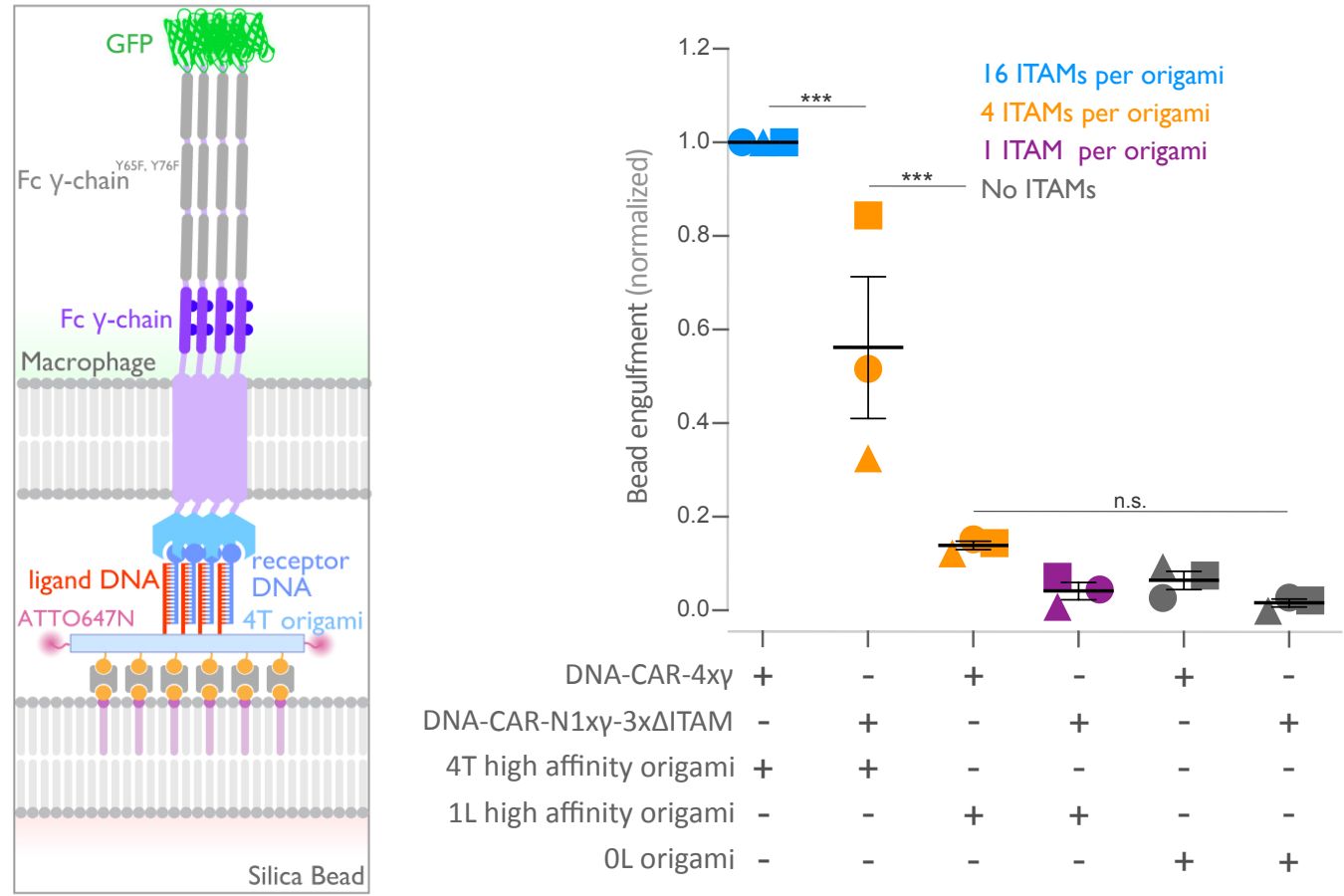